\title{
The Tumour Microenvironment after Radiotherapy: Mechanisms of Resistance and Recurrence
}

\author{
Holly E. Barker ${ }^{1}$, James T. E. Paget ${ }^{1}$, Aadil A. Khan ${ }^{1}$, and Kevin J. Harrington ${ }^{1}$ \\ ${ }^{1}$ Targeted Therapy Team, The Institute of Cancer Research, London, SW3 6JB, UK
}

\begin{abstract}
Radiotherapy plays a central part in curing cancer. For decades, most research on improving treatment outcomes has focussed on modulating radiation-induced biological effects on cancer cells. Recently, we have better understood that components within the tumour microenvironment have pivotal roles in determining treatment outcomes. In this Review, we describe vascular, stromal and immunological changes induced in the tumour microenvironment by irradiation and discuss how they may promote radioresistance and tumour recurrence. Subsequently, we highlight how this knowledge is guiding the development of new treatment paradigms in which biologically targeted agents will be combined with radiotherapy.
\end{abstract}

\section{Introduction}

Radiotherapy is used to treat up to $50 \%$ of cancer patients and to manage $40 \%$ of patients who are cured1. For decades, research into improving outcomes from radiotherapy focussed almost entirely on the cancer cell itself, ignoring complex biological interactions between the tumour and the stroma in which it grows - the so-called tumour microenvironment (TME). As a result, classical radiobiology largely failed to appreciate that the effects of radiotherapy on the TME, and the responses that are triggered within it, may be critical in determining the success or failure of therapy. Moreover, pre-clinical studies in some tumour models have suggested that radiotherapy-induced changes in the TME might, in fact, promote tumour invasion and spread in certain situations - even though decades of clinical experience have failed to show clear proof that radiotherapy promotes invasion and metastasis in patients. Thus, attempts to combine radiotherapy with new biologicallytargeted modalities were often predicated on their potential to enhance radiotherapy-induced cancer cell death, rather than their potential to re-engineer biological processes within the TME2.

Over the past two decades, this narrow radiobiological view has shifted to recognise the central importance of the TME3-5. The initial formulation of the hallmarks of cancer described cancers as complex tissues containing multiple cell types participating in heterotypic interactions with one another6. At around the same time, evidence that an irradiated stroma might favour tumour growth emerged with the observation that COMMAD cells [G], which are cells that exhibit several characteristics of normal mammary epithelial 
cells and are rarely tumorigenic, formed large tumours when implanted into pre-irradiated fat pads of syngeneic hosts7. Since then, a significant body of work has shown that radiation oncologists must take account of the TME, not only its ability to promote radioresistance and recurrence, but also as a legitimate therapeutic target in its own right.

Whilst a detailed explanation of the current state of understanding of the radiobiological model relating to radiotherapy has been reviewed elsewhere8, in this Review, we focus on mechanisms of radioresistance mediated by the tumour stroma and explore how these can be targeted to improve radiotherapy responses. We briefly discuss early and late radiotherapymediated effects on normal tissue, as normal tissue toxicity limits the dose of radiation that can be used in cancer treatment. With respect to tumours, we address the effects of radiotherapy on hypoxia, fibrotic responses and immune activation within the TME to understand how they may confer initial resistance or promote subsequent loco-regional or distant recurrence (Figure 1). At all stages, we will emphasise the potential for developing novel, mechanism-based, targeted therapies that will exert favourable effects on the TME.

\section{Effects of radiotherapy on the TME}

\section{Effects on the vasculature}

Possibly the best studied components of the TME with respect to radiation are endothelial cells and the tumour vasculature. Radiation induces endothelial cell dysfunction, characterised by increased permeability, detachment from the underlying basement membrane and apoptosis 9,10 . High single-fraction doses (8-16 Gy) have been linked to upregulation of acid sphingomyelinase (ASMase), which induces endothelial cell apoptosis11. Endothelial cell dysfunction and apoptosis contribute to post-irradiation inflammation and fibrosis. Within vessels, irradiation generates a pro-thrombotic state characterised by platelet aggregation, microthrombus formation and increased adhesion of inflammatory cells to endothelial cells with subsequent diapedesis into the perivascular space12.

Structurally, irradiation of the vasculature causes dose-dependent destruction of blood vessels, especially affecting microvasculature 13 . This reduced vascular density increases the distances between functioning vessels, meaning that some parenchymal tissues are not perfused. Over time irradiated blood vessels become thicker — primarily due to thickening of the intimal layer — and are prone to atherosclerosis [G]14-17. Other late morphological changes can occur including development of thrombosis, fibrosis, and medial necrosis [G]. Larger single-fraction radiation doses (15-20 Gy) may permanently reduce blood flow, suggesting irreversible changes to the vascular architecture18. Early and late responses of normal tissue to irradiation are dose-limiting factors in radiotherapy, affecting therapeutic efficacy as well as the quality of life of cancer patients (Figure 2).

Understanding the effect of radiation on the functional status of the tumour microvasculature is important for maximising the efficacy of radiotherapy. Radiotherapy-induced changes in the tumour vasculature remain dependent on total dose and fraction size, as well as the type, location and stage of the tumour itself19. Depending on how they are derived (i.e. through angiogenesis, vasculogenesis or vessel co-option [G]), tumour vessels may lack basement membrane and pericyte coverage rendering them more permeable and leaky and more 
radiosensitive than vessels in the surrounding normal tissue20. Endothelial cells within the TME are characterised by rapid proliferation rates, contributing to their inherent radiosensitivity. Each endothelial cell supports the growth of around 2,000 cancer cells21, and their response to radiotherapy — including mechanisms of recovery and survival have been the focus of research since they were first postulated as a critical target in tumour control. Similar to high dose irradiation of normal tissues11, single, large radiation doses have been shown to induce ASMase-dependent microvascular damage in fibrosarcoma and melanoma xenograft models in the first 6 hours with subsequent tumour cell death22.

Radiation-induced vascular damage potentiates tumour hypoxia and triggers immune responses through increased production of cytokines/chemokines that induce immune cell recruitment. Subsequent tumour revascularisation occurs via hypoxia-inducible factor-1a (HIF-1a)-dependent and -independent recruitment of bone marrow-derived cells (BMDCs)23-27.

\section{Effects on the stroma}

Chronic inflammation is the main driver of fibrosis, in which persistent immune responses occur alongside tissue remodelling and repair processes. Within normal tissues, infiltration of inflammatory cells triggers myofibroblast transformation, resulting in sustained production of growth factors (such as transforming growth factor $\beta$ (TGF- $\beta$ ) and connective tissue growth factor (CTGF)28, 29), proteolytic enzymes and angiogenic and/or fibrogenic cytokines that ultimately leads to excess deposition of components of the extracellular matrix (ECM) and scarring of the involved tissues30. The inflammatory processes that arise immediately after radiotherapy are not the same as those that appear decades later (Figure 2). Although the triggers in wound healing, normal tissue fibrosis and radiation fibrosis differ, the pathophysiological processes that ensue show some common features that implicate the immune system, the activation of stromal cells (such as myofibroblasts) and self-propagating signalling networks that result in a progressive phenotype31 (Box 1). As with radiotherapy-induced microvascular injury [G], prevention of fibroproliferative processes is important for maintaining normal organ function and, thus, improving quality of life following radiotherapy.

Cancer-associated fibroblasts (CAFs) are a heterogeneous cell population that comprise the majority of the cells within the stroma in many carcinomas. CAFs often have a spindleshaped, mesenchymal morphology and are classically identified as either fibroblast activation protein (FAP) and fibroblast specific protein (FSP)-positive fibroblasts or asmooth muscle actin (sma)-positive myofibroblasts, depending on their origin32. They secrete ECM proteins (such as tenascin C (TN-C) and collagen I), cytokines (e.g. hepatocyte growth factor (HGF), platelet-derived growth factor (PDGF) and chemokine (C-X-C motif) ligand 12 (CXCL12)), and matrix remodelling enzymes (such as matrix metalloproteinases (MMPs))33, 34. Unlike myofibroblasts that arise in response to inflammation or wound healing, CAFs may be resistant to apoptosis and irreversibly activated35. The heterogeneous nature of CAFs varies according to tumour type and stage of disease progression, and may also determine whether they exhibit tumour-promoting or inhibiting roles36. TGF- $\beta$ is a potent activator of fibroblasts and fibrocytes $37-39$ and is also a key CAF-secreted factor, 
along with CXCL12, that participates in autocrine signalling loops during tumour progression40. As well as cytokine-mediated activation, CAFs can obtain an activated phenotype through interaction with other cells in the TME, such as leukocytes and macrophages 41 .

Therapeutic irradiation of tumours will affect CAFs, but few detailed studies have been performed. Moreover, very few studies have used CAFs freshly isolated from human tumours. Hellevik et al. demonstrated that CAFs isolated from non-small cell lung cancer (NSCLC) samples survived ablative radiation but lost their tumour-invasive capability 42. They proposed that radiation impeded CAF mobility by stabilising focal contacts through increased integrin ( $\alpha 2, \beta 1$ and $\alpha 5)$ expression; formation of integrin-mediated attachments may facilitate CAF survival. Indeed, a number of preclinical studies have implicated $\beta 1$ integrin in tumour survival following radiotherapy43-45. More recently, it was proposed that $\beta 1$ integrin signalling in pancreatic cancer cells is required for stromal-mediated radioprotection46. Malignancies with a pronounced desmoplastic reaction [G] may therefore be inherently radioresistant due, in part, to integrin-mediated interactions between cancer cells, stromal cells and the surrounding ECM. In addition, integrin a $11 \beta 1$ has been shown to induce myofibroblast activation 47 and integrin $a \mathrm{~V} \beta 6$ was reported to be upregulated in irradiated lungs immediately prior to the onset of fibrosis48, suggesting that integrins may also be involved in the development of radiation fibrosis.

\section{Effects on the immune system}

Tumours evolve to evade immune recognition49, such that immune escape is now considered a 'hallmark of cancer'50. This, combined with other intrinsic and extrinsic survival-pressures such as resistance to hypoxia and rapid growth, likely results in the observed state of chronic inflammation51-53 and adaptive immunity suppression. This modulation is maintained by altered cytokine signalling (tumour necrosis alpha (TNF-a), interleukin (IL)- $1 \beta$, IL-6, IL-10 and TGF- $\beta 54,55$ ) and the recruitment of locally suppressive immune cells (TAMs56, myeloid derived suppressor cells (MDSCs) and $\mathrm{T}_{\text {regs }}[\mathrm{G}]$ ). After radiotherapy, a relative increase in these locally suppressive cell types, which are less radiosensitive than other lymphocyte subsets 57,58 , is counterbalanced by recruitment of circulating immune cells and increased antigen exposure and presentation. These changes profoundly affect the immune compartment of the TME, potentially re-priming it for an adaptive immune response.

After radiotherapy, inflammatory signals occur through activation of cell survival pathways and stimulation of the innate immune system $[\mathrm{G}]$. Both direct and indirect radiation effects [G] trigger inflammatory cytokine signalling (IL-1, TNF-a) and immune cell recruitment (for example, by endothelial cell expression of intercellular adhesion molecule 1 (ICAM-1), vascular cell adhesion molecule 1 (VCAM-1) and E-selectin). These events are principally co-ordinated by the intracellular actions of reactive oxygen species (ROS) and NF- $\mathrm{kB59}$. ROS also affect TNF signalling pathways60 and can activate NF- $\kappa B$, leading to further TNF-a production. The resulting cellular stress and death may also stimulate an immune response through the generation of damage-associated molecular patterns (DAMPs) [G] and their corresponding pattern recognition receptors (PRRs)59. 
The PRR family includes Toll-like receptors (TLRs), nucleotide binding oligomerisation domain-like receptors (NLRs), RIG-I-like receptors and C-type lectin receptors61. The recognition of pathogen-associated molecular patterns (PAMPs) [G] links stimuli from pathogenic sources to an inflammatory response. There is an analogous pathway that responds to endogenous damage via DAMPs, for example after radiotherapy62. DAMPs can be subdivided into three groups: those exposed on the surface (e.g. calreticulin); passively released substances (e.g. high-mobility-group box 1 (HMGB1) proteins); and those actively secreted (e.g. adenosine triphosphate (ATP))63. After tumour irradiation, a DAMP-PRRmediated damage response may lead to immunogenic cell death (ICD) [G] of cancer cells, changing the predominant TME cytokine profile towards an immunostimulatory one63, activating DCs and maturing them into effective antigen presenting cells (APCs)64. ICD is recognised as important for triggering an effective anti-tumour immune response (Figure 3). However, the overall effects of radiotherapy-induced ICD responses are complex. Checkpoint inhibition by $\mathrm{T}_{\text {regs }}$, whose expression of CTLA-465 affects the activation of CD8+ T-cells (Figure 3B), may still prevent the development of an effective adaptive immunity $[\mathrm{G}]$ to tumour cells. On the other hand, STAT- 1 , downstream of IFN- $\beta$ signalling, drives chemokine expression (notably CXCL9 and CXCL10) which recruits CXCR3positive T-cells66. Radiotherapy-induced CXCL16 expression in the vasculature of the TME also recruits CXCR6-positive activated CD8+ T-cells which have displayed anti-tumour effects in a murine breast cancer mode167. Radiotherapy-induced effects on the TME therefore also lead to enhanced immunostimulatory T-cell recruitment68, 69.

T-cell activation requires several signals: antigen in an appropriate major histocompatibility complex (MHC) binding to a T-cell receptor (TCR); co-stimulatory signals (e.g. from an APC); and background levels of cytokine stimulation. Negative feedback from up-regulation of CTLA-4 helps control this process by competitively inhibiting co-stimulatory signals from CD80 (also known as B7-1) and CD86 (B7-2) expressed on APCs to CD28 on Tcells65. Thus, radiotherapy acts to prime the immune system against cancer cells via ICD, but potentially remains constrained by the enhanced actions of suppressive immune cells. Overcoming these effects to harness the potential of the immune system against cancer cells can generate beneficial local and abscopal effects [G]. Unlocking abscopal effects in particular is the subject of a plethora of active research after case reports suggested that localised RT combined with immunomodulation may unlock the anti-metastatic potential of the adaptive immune system70-75.

In summary, complex reactions by the immune system to an irradiated TME are neither wholly immunostimulatory nor immunosuppressive. They comprise effects on cells intrinsic to the TME such as altered production of inflammatory cytokines, antigen exposure and DC priming as well as relative increases in radioresistant immunosuppressive macrophage and T-cell populations. Multifactorial signalling from both tumour ICD and radiotherapyinduced changes to endothelial cells also lead to an influx of circulating immune cells which are more immunostimulatory than those inherent to the TME. Therefore, radiotherapy is not a perfect mechanism for triggering ICD of cancer cells with subsequent effective adaptive responses. However, key events, such as the change in immunostimulatory cytokines, DC maturation/activation and T-cell recruitment and stimulation, mean that it does have the 
potential to prime potent responses against tumour cells if important immunosuppressive effects can be overcome.

\section{Targeting TME-mediated radioresistance}

Many strategies have been proposed for overcoming radioresistance in tumour cells2, but too little attention has been given to TME-mediated resistance mechanisms and how they might be circumvented. There are currently drugs which target various aspects of the TME being trialed as monotherapies or in combination with radiotherapy to treat cancer. For example, many drugs have shown efficacy against fibrosis but have so far not been tested for their ability to reduce radiotherapy-mediated late adverse effects in the TME or prevent tumour recurrence and metastasis. We hypothesise a number of these will improve the prognosis of patients after radiotherapy and also propose a number of immune and vascular targets that may show efficacy in radiosensitising the TME in future studies (Table 1).

\section{Targeting hypoxia}

Hypoxia is a key regulatory factor in tumour growth76 and has long been known to play a crucial role in radiotherapy resistance77 (Box 2). Most solid tumours contain zones where oxygen tensions fluctuate between almost anoxic ( $0 \%$ oxygen), hypoxic $(1 \% / 7.5 \mathrm{mmHg}$ oxygen) and normoxic (8\%/60 mmHg oxygen) 78 . High tumour cell proliferation rates and the abnormal structure of tumour vasculature lead to both chronic, diffusion-limited hypoxia and acute, transient, perfusion-limited hypoxia79, 80. Furthermore, changes in the TME as a result of radiotherapy can result in regions of cycling hypoxia81. Following radiotherapy, lack of oxygen reduces the production of reactive and cytotoxic species, such as ROS, and ultimately prevents irreparable DNA damage from occurring in cancer cells, preventing cancer cell death. Hypoxia also upregulates HIF-1a which independently promotes radioresistance (see below)82. Radioresistance manifests in oxygen tensions $<10 \mathrm{mmHg}$ and becomes maximal around $0.5 \mathrm{mmHg}$. Brizel et al. reported post-radiotherapy disease-free survivals of $78 \%$ in patients whose tumours had median oxygen tensions of $>10$ versus $22 \%$ in patients with median oxygen tensions of $<10 \mathrm{mmHg} 83$.

Therapeutic attempts to restore tumour oxygenation before or during radiotherapy have included red blood cell transfusion, erythropoietin administration, and hyperbaric oxygen (HBO) treatment84. Despite HBO treatment having a therapeutic benefit in patients with head and neck squamous cell carcinoma (HNSCC)77, inconsistent clinical trial data for other cancer types and huge logistical hurdles have impeded widespread uptake of this approach. Accelerated radiotherapy with carbogen and nicotinamide (ARCON) has since been developed to overcome tumour hypoxia and is currently being evaluated in Phase III clinical trials85-87. As yet, despite promising pre-clinical studies, clinical trials have ended with conflicting and inconclusive results with respect to improving local tumour control. Similarly, clinical trials of early nitroimidazole derivatives which act as oxygen mimetics in the radiochemical process have been inconsistent and severe dose-limiting toxic effects have restricted their development88-90. However, water-soluble compounds with improved toxicity profiles, such as doranidazole and nimorazole, have yielded survival benefits for NSCLC patients when used in combination with chemoradiotherapy in Phase I/II trials91 
and with radiotherapy in supraglottic and pharyngeal tumours in a Phase III study92.

Nimorazole in combination with radiotherapy is a standard-of-care treatment in Denmark and a phase III trial assessing this combination is currently recruiting in the UK93. Finally, a recent development in nanotechnology allows oxygen to be generated in hypoxic tumour regions by intratumoural injection of bioreactive albumin- $\mathrm{MnO}_{2}$ nanoparticles 94 . This therapy has been shown to improve tumour response to radiotherapy in preclinical studies 94 .

Irradiated tumours have elevated expression of HIF-1 (Box 2)95 and high tumour HIF-1 activity is an independent predictor of poor prognosis after radiotherapy96, 97. Furthermore, markers of both HIF-1 and HIF-2 hypoxia-response pathways are strongly associated with radiotherapy failure in head and neck cancer98. A number of drugs have been designed to inhibit HIF-1 activity and may affect radiosensitivity. Acriflavine directly binds the HIF-1a subunit, thereby inhibiting HIF-1 dimerisation and transcriptional activity99. Acriflavine has been shown in preclinical studies to downregulate mRNA expression of VEGF, CXCL12 and stromal cell factor $(S C F)$ and reduce tumour vasculature99. Another HIF-1 inhibitor, YC-1, improved treatment outcome when administered after radiation100. Stabilisation of the HIF-1a subunit can also occur through increased levels of TGF- $\beta$ in the TME. TGF- $\beta$ has an important role in maintaining normal vascular homeostasis and has been shown to stimulate angiogenesis in irradiated environments 101 . However, as TGF- $\beta$ can promote both pro- and anti-angiogenic effects 102 , strategies that target TGF- $\beta$ directly are likely to be challenging.

As previously discussed, tumours contain abnormal vessels that contribute to tumour hypoxia. Vessel normalisation to increase radiotherapy response and reduce tumour recurrence and metastasis is currently being investigated103 (Figure 4). VEGF-A is the principal angiogenic molecule implicated in development of abnormal vasculature in the TME104. Pharmacological inhibition of VEGF has been achieved with an anti-VEGF antibody (bevacizumab), a VEGF-trap molecule (aflibercept, which targets all VEGF molecules and placental growth factor, PIGF), a VEGF receptor (VEFGR)-inhibiting antibody (DC101), and receptor tyrosine kinase inhibitors (TKIs, sunitinib, sorafenib, pazopanib)105. Although disappointing results have been observed for anti-VEGF monotherapy, treated tumours were sensitised to chemotherapy and radiotherapy due to better drug delivery and reduced hypoxia, respectively106. TKIs have also been shown to contribute to vessel normalisation in many preclinical models and synergise with radiation in orthotopic models of GBM, melanoma, and colon, lung, and head and neck cancer84. AntiVEGF effects are somewhat transient, however, and targeting the downstream molecules PI3K and mTOR (using NVP-BEZ235 and NVP-BGT226) in combination with radiotherapy could prove to be more efficacious through durable vessel normalisation 107. Vessel normalisation occurs during a specific time-window following different antiangiogenic treatments and this translates into optimal tumour growth delay when radiotherapy is scheduled accordingly 108,109 . Similarly, the dose of anti-angiogenic compounds used in combination therapy needs to be carefully considered. Carmeliet and Jain proposed that higher doses of anti-angiogenic therapy could be harmful as a result of normal tissue toxicity and complete vessel destruction, which may paradoxically increase tumour hypoxia110. 
Two endogenous angiogenesis inhibitors, angiostatin and endostatin have synergistic antitumour effects in combination with radiotherapy84. Likewise, TNP-470, the synthetic analogue of a naturally occurring antibiotic, arrests endothelial cell growth and improves tumour oxygenation and response to radiotherapy111-113. Angiostatin and TNP-470 are no longer in clinical trials, due to poor toxicity profiles, lack of efficacy, and the development of more effective anti-angiogenic drugs. Endostar, however, a more potent and stable version of endostatin114, improves radiation responses in preclinical cancer models through inhibition of VEGF, TGF- $\beta$, HIF-1 $a$ and bFGF115, 116 and is currently being combined with radiotherapy in Phase II clinical trials.

Blocking vasculogenesis may also improve radiotherapy-mediated local tumour control and prevent recurrence117 (Figure 4). In their preclinical study, Kioi et al. abrogated BMDCmediated tumour vasculogenesis through inhibition of HIF-1 activity using NSC-3475425. Likewise, administration of AMD3100, which inhibits the interaction between CXCL12 and CXCR4, prevented blood flow returning to irradiated tumours and completely inhibited recurrence for up to 100 days. A similar effect was observed with a CXCR4 neutralising antibody. Another preclinical study has implicated Angiopoietin 2 (ANG-2; a molecule proposed to compensate for VEGF inhibition by recruiting perivascular BMDCs to support the weak tumour vasculature) in tumour vasculogenesis. Burrell et al. demonstrated that treatment with an inhibitor of both ANG-1 and ANG-2, AMG386, prevented the influx of perivascular BMDCs to the central vasculature and it was hypothesised that ANG-2 inhibition may overcome resistance to anti-VEGF therapies and prevent tumour recurrence following RT118.

Finally, as with CAF-associated integrins, the role of integrins in mediating cell-ECM attachment is important for endothelial cell survival and migration. Early studies revealed that radiotherapy up-regulated integrin av $\beta 3$ expression in endothelial cells and concurrent treatment with an av $\beta 3$ antagonist could enhance radiotherapy-mediated anti-angiogenic and anti-tumour responses in xenograft models119. Integrin inhibitors have been developed (cilengitide against $\operatorname{av} \beta 3 / \operatorname{av} \beta 5$, vitaxin against $\operatorname{av} \beta 3$, and volociximab against a $5 \beta 1$ ) and shown efficacy alone or in combination with radiotherapy in preclinical and clinical studies. Cilengitide showed encouraging activity in a phase II trial120, but has not improved outcomes for patients with GBM in a phase III trial with chemoradiotherapy121.

Nevertheless, further trials are ongoing (Supplementary Table). Likewise, volociximab and vitaxin have anti-angiogenic activity but data on their radiosensitising capabilities are lacking122-124.

In conclusion, direct and indirect therapeutics to reduce tumour hypoxia have been developed and show preclinical promise in combination with radiotherapy. However, changes in the TME during therapy and complex issues relating to drug dose and schedule mean that we do not yet know how best to employ these agents for clinical benefit.

\section{Targeting the stroma}

Inhibition of RT-induced inflammatory responses may reduce long-term fibrotic processes that could be important if complete eradication of local tumour cells is not achieved. Upregulation of pro-inflammatory NF- $\kappa \mathrm{B}$ post-irradiation is often associated with increased 
IL-1 $\beta$, IL-6, IL-8, granulocyte-macrophage colony-stimulating factor (GM-CSF) and COX-2 in the TME125. Therefore, developing inhibitors that interfere with this inflammatory network has been a focus of radiosensitisation approaches. Many natural and synthetic antiinflammatory compounds have proven efficacious in tumour radiosensitisation 125. However, their effects have been mediated through anti-angiogenic, anti-tumour cell survival, or decreased BMDC mobilisation mechanisms rather than through inhibition of fibrotic processes. It must also be borne in mind that attempts to reduce inflammation as a means of preventing tumour-promoting fibrotic reactions may have deleterious knock-on consequences for the beneficial effects of inflammation on anti-tumour immunity, which will be discussed later.

TGF- $\beta$ signalling is augmented by radiotherapy 126 and is a key inducer of stromal activation in the TME. Within the context of the post-radiotherapy TME, direct modulation of TGF- $\beta$ is complex. Although it has been shown to directly mediate tumour suppression in irradiated environments 127 , inhibition of TGF- $\beta$ in conjunction with radiotherapy has also delayed tumour growth and prevented radiotherapy-mediated increases in circulating levels of TGF- $\beta$, thereby reducing cancer metastasis in preclinical models128, 129. Although these studies mainly focussed on TGF- $\beta$-mediated effects on the tumour cells, the increased levels of circulating TGF- $\beta$ observed following irradiation may be a consequence of CAF activation and could also influence tumour progression through further modulation of CAF activity. So far, TGF- $\beta$ inhibition, in isolation, has not proven effective in the clinic130. The broad and often opposing activities of TGF- $\beta$ can pose problems in targeting strategies and more targeted inhibition of downstream molecules may be more beneficial. Indeed, preclinical studies of a TGF- $\beta$ R 1 inhibitor, SD-208, showed reduced tumour growth and decreased fibrosis in the TME131. There is, therefore, a rationale for combining it with radiotherapy in order to prevent radiation-induced activation of CAFs.

Molecules secreted by CAFs, such as HGF and TN-C, could be promising selective targets in the tumour stroma to negate radiotherapy-induced fibrotic phenotypes that may facilitate radioresistance (Figure 4). Monoclonal antibodies against HGF and MET (also known as hepatocyte growth factor receptor, HGFR) and MET small molecule inhibitors have shown efficacy in clinical trials132. Preclinical studies have demonstrated that MET inhibition enhances radiotherapy responses and prevents tumour cell invasion mediated by CAFderived HGF secretion following irradiation133, 134. However, HGF and MET inhibitors have yet to be combined with radiotherapy in the clinic. Alternatively, high stromal expression of TN-C, as a result of CAF activation, can be targeted with the 131I-labelled anti-TN-C antibodies 81C6 and F16SIP. A phase II clinical trial demonstrated some success for combining $81 \mathrm{C} 6$ with radiotherapy 135,136 and a phase III trial has since been proposed137.

A number of agents with anti-fibrotic actions may impact on radiotherapy-mediated inflammation and fibrosis in the TME. Imatinib, nilotinib and dasatanib inhibit TGF- $\beta$ and PDGF signalling and, hence, collagen synthesis138. They are currently being evaluated in clinical trials for the treatment of fibrosis. Other inhibitors affecting growth factor signalling include BIBF1000 and BIBF1120, which target PDGFR, VEGFR and bFGFR. These molecules have some efficacy in treating idiopathic pulmonary fibrosis139, 140 and may 
modulate post-irradiation changes in the TME. Hedgehog $(\mathrm{Hh})$ signalling also regulates fibrosis141 and has been implicated in the desmoplastic reaction in pancreatic ductal adenocarcinoma142. Attempts to target this pathway have led to the development of inhibitors (vismodegib, saridegib, sonidegib) of the downstream molecule smoothened (SMO). Monotherapy preclinical and clinical trials had encouraging outcomes143-145, and results of early studies combining vismodegib with radiotherapy146 are also promising. Phase II clinical trials of radiotherapy plus Hh inhibition are ongoing (Supplementary Table).

Targeting growth factors involved in the activated networks in the TME has led to the development of suramin, which inhibits PDGF, EGF, TGF- $\beta$, FGF-2 and IGF signalling 147. Suramin has exhibited anti-proliferative effects against many advanced cancers 148. Although suramin did not improve survival when combined with cranial radiotherapy in patients with glioblastoma149, the combination is yet to be tested in cancers in which an activated stroma is common, such as breast and pancreatic cancer. Interestingly, suramin was recently shown to inhibit heparanase enzymes, thereby reducing tissue damage and fibrosis in a rat model of hepatocellular carcinoma150. Heparanase is involved in ECM breakdown and regulates the bioavailability of growth factors and cytokines in the TME151. Most importantly, heparanase has been shown to augment radiation-induced cancer cell invasion152. An inhibitor of heparanase, SST0001, has shown potential in preclinical studies where it reduced the spread of pancreatic cancers in combination with radiotherapy 152. Other heparanase inhibitors, PG545, M402 and PI-88, have also displayed anti-tumour activity in murine models and have entered clinical trials153-155. The activity of heparanase is also regulated indirectly by MMPs151. Many MMP inhibitors, including marimastat, prinomastat, batimastat and tanomastat, have been evaluated in clinical trials for the treatment of various cancers, mostly with disappointing results156. The broad-spectrum activity of MMP inhibitors may explain their failure in monotherapy clinical trials. Preclinical studies with more specific MMP inhibition have demonstrated some improvement in the efficacy of radiotherapy (e.g. MMP-2 inhibition has been shown to abrogate radiotherapy-induced tumour invasion and progression157-160), indicating further research is required.

CAFs are generally genetically more stable than tumour cells, making them good therapeutic targets. However, they display functional duality, making the balance between tumour inhibition and promotion very delicate. For example, a recent report by Özdemir and colleagues demonstrated that CAF depletion in a mouse model of pancreatic cancer may actually accelerate cancer progression 161 . This suggests that care needs to be taken when targeting CAFs specifically and blocking downstream mediators of CAF activation may prove to be more efficacious. Whether desmoplasia provides a growth disadvantage for cancer cells or promotes their dissemination is also still under debate. Nevertheless, promising results from trials involving inhibitors of ECM turnover suggest agents developed for the treatment of fibrotic diseases may enhance radiotherapy-mediated tumour growth delay and reduce subsequent TME changes that could facilitate tumour cell migration and cancer spread. 


\section{Immune modulation}

Much of the current interest in combining immunomodulation and radiotherapy lies in strategies to overcome the persistent suppression of adaptive immune responses by the tumour and its microenvironment. Of particular interest is the promise of the abscopal effect, whereby localised radiotherapy acts as the catalyst for systemic anti-tumour immunoreactivity 74,75 .

Whilst radiotherapy does lead to ICD, some tumours exhibit accelerated tumour repopulation by paracrine caspase 3-dependent $\mathrm{PGE}_{2}$-mediated signalling162. Signalling from surviving and recruited MDSCs and TAMS also suppress T-cell function through antagonistic cytokine signals, such as IL-6, IL-10 and TGF- $\beta 163$. Their relevance is highlighted in a phase I/II clinical trial combining radiotherapy and a primed DC vaccine against high-risk soft-tissue sarcoma. A 52.9\% rate of tumour-specific immune responses was reported, but non-responders had significantly higher levels of tumour MDSCs prior to immunisation164.

Manipulation of the TLR response can increase activation of DCs, triggering an effective adaptive immune response after radiotherapy 165 . Direct TLR manipulation is currently being trialled using the TLR7 agonist, imiquimod, which is approved for basal cell skin carcinomas and melanomas. Imiquimod is being used in conjunction with local radiotherapy as a topical treatment against breast cancer metastasis with promising preclinical data166. Using cancer vaccines comprising TLR agonists with tumour antigens to stimulate DCs and T-cell responses has been effective in preclinical models and has been translated clinically167. GM-CSF has also been used in the clinic, combined with radiotherapy, to treat patients with metastatic disease across multiple cancer types (lung, thyroid, eccrine [G], cervical and breast cancer) 168 . In that study, patients treated with chemotherapy received radiotherapy ( $35 \mathrm{~Gy}$ in 10 fractions) delivered to a metastatic site followed by daily subcutaneous injections of GM-CSF for 14 days after the first week of radiotherapy. A systemic effect was seen in $27 \%$ of patients, with a corresponding improvement in survival in those who experienced abscopal effects (median overall survival of 25 months versus 10 months).

Effective T-cell activation requires both antigen presentation and co-stimulation from an appropriate APC. Several of the steps that regulate this process, including CTLA-4, OX40, PD-1 and CD137, are likely to represent important targets for immunomodulation after radiotherapy-induced immune priming. Ipilimumab (anti-CTLA-4 monoclonal antibody) is approved in advanced-stage melanoma, having improved survival in phase III trials169, 170. In murine studies, unilateral radiotherapy and systemic anti-CTLA-4 blockade delayed the growth of a contralateral, unirradiated tumour171. Interestingly, this abscopal response was dependent on radiation dose-fractionation with 24 Gy delivered in 3 fractions appearing to be optimal171. This suggests there may be preferred fractionation schemes for effective immune priming, although the evidence for this is limited at the moment (see also table 2) and may well differ according to therapeutic agent and tumour histology. Scheduling of immunological therapy relative to radiotherapy is also likely to be important, with an initial period of tolerance seen after radiotherapy (Table 2). Indeed, there is some early evidence that an interval of around 1 month between radiotherapy and immunomodulation may be 
optimal for synergy (Table 2). Anecdotal clinical reports of radiation-induced abscopal responses have been published and results from ongoing clinical trials are eagerly awaited (Supplementary Table).

OX40 signalling co-stimulates activation of several T-cell subtypes (e.g. CD4+ and CD8+). It mediates positive feedback, potentiating activation and, thus, polarising the T-cell response. In combination with radiotherapy, where CD8+ priming/activation already occurs, activation of OX40 signalling might be particularly effective. In a murine model, OX40 agonistic antibodies improved local control after surgery or radiotherapy 172. It is also thought that OX40 can help prime low affinity T-cells and reverse T-cell tolerance. As such, activating OX40 signalling might work synergistically with CTLA-4 blockade to activate Tcells post-radiotherapy173. T-cell co-stimulating proteins, such as CD137 (4-1BB)174, also represent promising targets.

Induced CD-8+ T-cell exhaustion is a radioresistance mechanism (Figure 4). This has been characterised in a murine model of lymphocytic chorio-meningitis virus-13 (LCMV-13) infection in comparison to normal, uninfected T-cells175. Similarities between virallyinduced T-cell exhaustion and ineffective T-cells in melanoma have been studied176.

Markedly different gene expression was seen in cancer-infiltrating CD8+ T-cells and those in the circulation, with patterns similar to the exhaustion profiling seen in the LCMV-13 murine model. Modulation of these exhaustion pathways by targeting programmed death-1 (PD-1), T-cell immunoglobulin mucin-3 (TIM3)177, or lymphocyte activation gene-3 (LAG3)178 expression represents an exciting area for combination with radiotherapy. Thus far, of these exhaustion pathways, the PD-1 receptor ligand PD-L1/PD-1 axis has been the best studied in the context of radiotherapy and immune-modulation. Expression of PD-1 on T-cells in the TME is suggestive of their exhaustion and results in ineffective T-cellmediated immune responses. Upregulation of PD-L1 on tumour cells after irradiation179 also represents a mechanism of radioresistance. Blockade of the PD-L1/PD-1 axis in combination with radiotherapy is effective at the primary tumour site and in generating abscopal responses in AT-3 mammary tumours180. Early clinical results using this strategy against incurable metastatic breast cancer also look promising 181 .

Oncolytic viruses preferentially infect and replicate in tumour cells, leading to cell death 182 . They are also recognised as potent immune therapeutics183. When combined with radiotherapy, they have demonstrated synergy in preclinical models 184,185 . In early clinical trials of radiotherapy and oncolytic virus combinations, we reported a tolerable toxicity profile that does not overlap with radiotherapy-induced side-effects186. In the TME, oncolytic virus infection triggers a PAMP/DAMP-related PRR signal162, 187 and could potentially play a role in ICD, immunomodulation and T-cell activation. This viral response may represent another method of overcoming the TME's suppression of adaptive immune responses.

Viruses can also be used to deliver therapeutic genes that exert immunomodulatory effects. Examples include the over-expression of chemokines (CCL3 and CCL5), immune cytokines (GM-CSF, IL-2, IL-4, IL-12) and T-cell co-stimulators (CD40L, CD80, 4-1BBL). Talimogene laherparepvec (T-Vec) is a replication-competent GM-CSF-expressing herpes 
simplex virus that has been tested in a phase I clinical trial in combination with chemoradiotherapy in head and neck cancer186, 188. The combination of viral oncolysis, immune stimulation and immunomodulation may represent a powerful approach that is worthy of further evaluation.

\section{Conclusions}

Radiotherapy leads to the activation of an interconnected series of processes in the TME: inflammation, cycling hypoxia, immunomodulation, revascularisation, CAF co-ordinated ECM remodelling, and fibrosis. These changes occur in the TME in an interconnected fashion (Figure 5). This is highlighted by the overlapping and widespread effects of several factors - especially growth factors TGF- $\beta$, VEGF and PDGF; cytokines TNF- $a$, CXCL12, IL-1, IL-2, IL-6 and IL-10; and transcription factors NF- $\mathrm{kB}$ and HIF-1 (Figure 1).

Against this background, emerging therapeutic strategies have aimed to tip the balance of the TME-radiotherapy response towards more effective cancer therapy, whilst minimising adverse effects (Figure 4). Hypoxia directly affects initial radiosensitivity, immune responses and promotes the development of neovasculature. It also stimulates ongoing CAF activity. Strategies currently under development to increase tumour oxygenation, for example by modulating oxygen availability or by normalising tumour vasculature, demonstrate great potential. Furthermore, targeting HIF-1 could have TME-wide benefits, particularly through its modulation of TGF- $\beta$ signalling. Related strategies to prevent BMDC-mediated tumour revascularisation by using CXCL12 inhibitors also appear to be very promising and are now in early clinical trials (Supplementary Table). Integrins, central to the survival and repopulation of both ECs and CAFs after radiotherapy, are also important emerging targets (Table 1).

Targeting drivers of the initial inflammatory response, such as NF- $\kappa \mathrm{B}, \mathrm{COX}-2$ and TNF- $\mathrm{a}$, have been shown to decrease radiotherapy-mediated side-effects in surrounding normal tissues without improving tumour responses. Moreover, targeting inflammation may counteract the anti-tumour benefits of immunomodulation. Therefore, in this regard, emphasis should be placed on reducing late radiation effects on ECM structure rather than the initial inflammatory response. Abrogating excess ECM production by specifically targeting CAFs with anti-FAP antibodies has, so far, not shown efficacy in cancer trials. Indeed, depleting the CAF population may prove detrimental in some tumour types. It may be more beneficial to prevent ECM remodelling events in the TME, either through prevention of ECM cross-linking or breakdown. Many molecules impeding ECM remodelling, such as inhibitors of growth factors, their receptor kinases, hedgehog signalling and matrix enzymes, are currently being used to treat fibrotic disorders and may show efficacy in preventing the development of a radiotherapy-mediated invasive environment (Table 1). Possibly the most exciting development in modulation of the tumour ECM is the generation of heparanase-targeted therapies which aim to prevent tumour cell dissemination by modulating ECM remodelling and reducing availability of growth factors and cytokines in the TME. 
With respect to immune modulation, the most promising areas of development are in generating an effective adaptive response both to treat cancer locally and abscopally. The strategies involved can be summarised as: increasing ICD, and both numbers and activation levels of DCs, using a combination of cytokines, growth factors and TLR stimuli; appropriate recruitment, activation of T-cells with primed DCs; and the abrogation of inhibitory signalling (CTLA-4) and T-cell exhaustion (PD-L1/PD-1). A number of these approaches are now in clinical development both as single-agents and combined with preexisting chemotherapy and other TME modulators (Supplementary Table). New strategies are also emerging rapidly and warrant investigation (Table 1): chemokine recruitment of anti-tumour T-cell subgroups (for example using CXCL16), targeting T-cell exhaustion markers (such as TIM3 and LAG3), and oncolytic immunotherapies (including gene therapy to deliver immunomodulation).

Investigation of the TME-radiotherapy response has led to the development of an exciting array of novel treatments. Given the timing and interplay of events in the response of the TME to radiotherapy, it will be a significant challenge to develop rational radiotherapy-drug combinations in this field. Nonetheless, we believe that carefully designed combinations of radiotherapy with vascular normalisation, immunomodulation and anti-fibrotic therapy will prove effective in maximising therapeutic benefits and minimising both unwanted off-target effects and the possibility of metastasis and recurrence. While many questions remain, we believe that the door is beginning to open on the synergistic potential that will be the future of cancer therapy.

\section{Supplementary Materials}

Refer to Web version on PubMed Central for supplementary material.

\section{Biographies}

Holly E. Barker is a Post-doctoral Training Fellow in the Targeted Therapy Team at the Institute of Cancer Research in London, UK. She currently studies inhibitors of the DNA damage repair response and their roles in the radiosensitisation of head and neck cancers. In her previous Post-doctoral position she studied the role of hypoxia-regulated enzymes in CAF activation and ECM remodelling during breast cancer progression and metastasis.

James Paget is a PhD student in the Targeted Therapy Team at the Institute of Cancer Research and a Clinical Research Fellow in plastic surgery at The Royal Marsden Hospital in London, UK. He currently studies the role of virally delivered gene therapy immunomodulation in radioprotecting microvascularly transferred autologous tissue within the context of breast cancer reconstruction.

Aadil Khan is a clinical lecturer in plastic surgery at the Institute of Cancer Research and The Royal Marsden Hospital in London. His research interests include the development of late adverse effects in patients undergoing reconstructive procedures using free tissue transfer and free flap gene therapy. 
Kevin J. Harrington is Joint Head of the Division of Radiotherapy and Imaging, Lead for the Radiotherapy Theme of the Royal Marsden Hospital/Institute of Cancer Research NIHR Biomedical Research Centre and Team Leader for the Targeted Therapy Team at The Institute of Cancer Research. His research interests include the development of preclinical and clinical models of radiosensitisation and the development of oncolytic viruses as cancer therapeutics. He is an honorary consultant in clinical oncology at The Royal Marsden Hospital, specialising in head and neck and skin cancers.

\section{Glossary}

\section{Adaptive immunity}

a carefully regulated, adaptable, specific immune response comprising humoral- and cellmediated components. It is capable of both systemic actions and immunological memory to specific stimuli. It is triggered by known antigens or by appropriate antigen presentation from the innate immune system.

\section{Atherosclerosis}

thickening of the artery wall as a result of white blood cell invasion and accumulation.

\section{Abscopal effects}

irradiation of tumour cells or the adjacent extracellular matrix (ECM) can induce biologically relevant changes in distant cells, which may or may not have been irradiated themselves. These are distinguished from bystander (which refers to changes affecting nearby unirradiated cells) and cohort effects (which refer to changes affecting off-target irradiated cells).

\section{COMMA-D cells}

an epithelial cell line derived from the mammary tissue of a mid-pregnant BALB/c mouse, which exhibits many characteristics distinctive of normal mammary epithelial cells.

\section{Damage-associated molecular patterns (DAMPs)}

stimuli released by stressed, dying or injured cells that may trigger an inflammatory response by activation of a number of pattern recognition receptors (PRRs).

\section{Desmoplastic reaction}

a stromal reaction that can be induced by tissue injury, wound repair or cancer growth. Increased ECM and growth factor production and secretion result in the formation of scarlike fibrotic tissue.

\section{Direct and Indirect effects}

radiation damage can be divided into direct effects, where the damage is a result of the ionising radiation itself, and indirect effects, which refer to the resultant changes in cellular pathways as a result of radiation for example as a result of ROS.

\section{Eccrine (tumour)}

tumour type from secretory sweat glands.

\section{Immune tolerisation}


The recognition of "self" and "non-self" during antigen presentation is important and carefully regulated to prevent autoimmunity, tolerisation is the process of recognising antigens as "self".

\section{Immunogenic cell death}

cell death that triggers an immune reaction by DAMP/PRR signalling. This may occur as a result of different types of tissue damage, for example RT or chemotherapy.

\section{Innate immune system}

the initial immune response which occurs in a generic fashion to inflammatory stimuli, comprising complement activation and immune cell recruitment and activation. It coordinates the activation of the adaptive immune system by antigen presentation.

\section{Medial necrosis}

necrosis of the middle portion of vessel walls (anatomically called the tunica media).

\section{Microvascular injury}

injury to the fine network of blood vessels and capillaries resulting in changed patterns of blood flow.

\section{Pathogen-associated molecular patterns (PAMPs)}

signalling from pathogens by particular stimuli that can be recognised by immune cells leading to an inflammatory response.

\section{Pleiotropic cytokines}

Cytokines whose actions are context dependent with relation to a particular process or pathway, that is to say in some circumstances they may be stimulatory in others inhibitory.

\section{TAMS}

Tumour associated macrophages are macrophages associated within the tumour microenvironment, they are largely immunosuppressive and resemble the alternatively activated "M2" macrophage.

$\mathbf{T}_{\text {reg }}$ cells

Regulatory T-cells are a T-cell subset that exert immunosuppressive and tolerising effects and have an important role in cancer immune editing, the maintenance of a permissive cancer microenvironment and in preventing effective adaptive immune recognition of tumour cells.

\section{Vessel co-option}

a mechanism by which tumours obtain a blood supply by hijacking the existing vasculature.

\section{References}

1. Harrington KJ, et al. Guidelines for preclinical and early phase clinical assessment of novel radiosensitisers. Br J Cancer. 2011; 105:628-639. [PubMed: 21772330]

2. Camphausen K, Tofilon PJ. Combining radiation and molecular targeting in cancer therapy. Cancer Biol Ther. 2004; 3:247-50. [PubMed: 15107611] 
3. Barcellos-Hoff MH, Park C, Wright EG. Radiation and the microenvironment - tumorigenesis and therapy. Nat Rev Cancer. 2005; 5:867-75. [PubMed: 16327765]

4. Demaria S, Bhardwaj N, McBride WH, Formenti SC. Combining radiotherapy and immunotherapy: a revived partnership. Int J Radiat Oncol Biol Phys. 2005; 63:655-66. [PubMed: 16199306]

5. Durand RE. The influence of microenvironmental factors during cancer therapy. In Vivo. 1994; 8:691-702. [PubMed: 7727714]

6. Hanahan D, Weinberg RA. The hallmarks of cancer. Cell. 2000; 100:57-70. [PubMed: 10647931]

7. Barcellos-Hoff MH, Ravani SA. Irradiated mammary gland stroma promotes the expression of tumorigenic potential by unirradiated epithelial cells. Cancer Res. 2000; 60:1254-60. [PubMed: 10728684] [This paper demonstrates that radiotherapy-mediated changes in ECM composition and growth factor activities in the TME can contribute to neoplastic progression.]

8. Good JS, Harrington KJ. The hallmarks of cancer and the radiation oncologist: updating the 5Rs of radiobiology. Clin Oncol (R Coll Radiol). 2013; 25:569-77. [PubMed: 23850153]

9. Heckmann M, Douwes K, Peter R, Degitz K. Vascular activation of adhesion molecule mRNA and cell surface expression by ionizing radiation. Exp Cell Res. 1998; 238:148-54. [PubMed: 9457067]

10. Langley RE, Bump EA, Quartuccio SG, Medeiros D, Braunhut SJ. Radiation-induced apoptosis in microvascular endothelial cells. Br J Cancer. 1997; 75:666-72. [PubMed: 9043022]

11. Paris F, et al. Endothelial apoptosis as the primary lesion initiating intestinal radiation damage in mice. Science. 2001; 293:293-7. [PubMed: 11452123]

12. Wang J, Boerma M, Fu Q, Hauer-Jensen M. Significance of endothelial dysfunction in the pathogenesis of early and delayed radiation enteropathy. World J Gastroenterol. 2007; 13:3047-55. [PubMed: 17589919]

13. Baker DG, Krochak RJ. The response of the microvascular system to radiation: a review. Cancer Invest. 1989; 7:287-94. [PubMed: 2477120]

14. Gujral DM, Chahal N, Senior R, Harrington KJ, Nutting CM. Radiation-induced carotid artery atherosclerosis. Radiother Oncol. 2014; 110:31-8. [PubMed: 24044796]

15. Hoving S, et al. Single-dose and fractionated irradiation promote initiation and progression of atherosclerosis and induce an inflammatory plaque phenotype in ApoE(-/-) mice. Int J Radiat Oncol Biol Phys. 2008; 71:848-57. [PubMed: 18514779]

16. Russell NS, et al. Novel insights into pathological changes in muscular arteries of radiotherapy patients. Radiother Oncol. 2009; 92:477-83. [PubMed: 19541382]

17. Stewart FA, et al. Ionizing radiation accelerates the development of atherosclerotic lesions in ApoE-/- mice and predisposes to an inflammatory plaque phenotype prone to hemorrhage. Am J Pathol. 2006; 168:649-58. [PubMed: 16436678]

18. Chin MS, et al. Skin perfusion and oxygenation changes in radiation fibrosis. Plast Reconstr Surg. 2013; 131:707-16. [PubMed: 23542244]

19. Park HJ, Griffin RJ, Hui S, Levitt SH, Song CW. Radiation-induced vascular damage in tumors: implications of vascular damage in ablative hypofractionated radiotherapy (SBRT and SRS). Radiat Res. 2012; 177:311-27. [PubMed: 22229487]

20. Jain RK. Molecular regulation of vessel maturation. Nat Med. 2003; 9:685-93. [PubMed: 12778167]

21. Denekamp J. Vascular endothelium as the vulnerable element in tumours. Acta Radiol Oncol. 1984; 23:217-25. [PubMed: 6208746]

22. Garcia-Barros M, et al. Tumor response to radiotherapy regulated by endothelial cell apoptosis. Science. 2003; 300:1155-9. [PubMed: 12750523] [This paper reports the requirement of acid sphingomyelinase for endothelial cell sensitivity to radiotherapy and also demonstrates that microvascular damage is important for tumour response to radiotherapy.]

23. Ahn GO, Brown JM. Influence of bone marrow-derived hematopoietic cells on the tumor response to radiotherapy: experimental models and clinical perspectives. Cell Cycle. 2009; 8:970-6. [PubMed: 19270527]

24. Begg AC, Stewart FA, Vens C. Strategies to improve radiotherapy with targeted drugs. Nat Rev Cancer. 2011; 11:239-53. [PubMed: 21430696] 
25. Kioi M, et al. Inhibition of vasculogenesis, but not angiogenesis, prevents the recurrence of glioblastoma after irradiation in mice. J Clin Invest. 2010; 120:694-705. [PubMed: 20179352] [This paper demonstrates that irradiation induces tumour vasculogenesis through HIF-1and CXCL12-mediated BMDC recruitment in a GBM xenograft model.]

26. Kozin SV, et al. Recruitment of myeloid but not endothelial precursor cells facilitates tumor regrowth after local irradiation. Cancer Res. 2010; 70:5679-85. [PubMed: 20631066]

27. Lerman OZ, et al. Low-dose radiation augments vasculogenesis signaling through HIF-1dependent and -independent SDF-1 induction. Blood. 2010; 116:3669-76. [PubMed: 20631377]

28. Gressner OA, Gressner AM. Connective tissue growth factor: a fibrogenic master switch in fibrotic liver diseases. Liver Int. 2008; 28:1065-79. [PubMed: 18783549]

29. Verrecchia F, Mauviel A. Transforming growth factor-beta and fibrosis. World J Gastroenterol. 2007; 13:3056-62. [PubMed: 17589920]

30. Wynn TA. Cellular and molecular mechanisms of fibrosis. J Pathol. 2008; 214:199-210. [PubMed: 18161745]

31. Yarnold J, Brotons MC. Pathogenetic mechanisms in radiation fibrosis. Radiother Oncol. 2010; 97:149-61. [PubMed: 20888056]

32. Kidd S, et al. Origins of the tumor microenvironment: quantitative assessment of adipose-derived and bone marrow-derived stroma. PLoS One. 2012; 7:e30563. [PubMed: 22363446]

33. Kalluri R, Zeisberg M. Fibroblasts in cancer. Nat Rev Cancer. 2006; 6:392-401. [PubMed: 16572188]

34. Spaeth EL, et al. Mesenchymal stem cell transition to tumor-associated fibroblasts contributes to fibrovascular network expansion and tumor progression. PLoS One. 2009; 4:e4992. [PubMed: 19352430]

35. Li H, Fan X, Houghton J. Tumor microenvironment: the role of the tumor stroma in cancer. J Cell Biochem. 2007; 101:805-15. [PubMed: 17226777]

36. Augsten M. Cancer-associated fibroblasts as another polarized cell type of the tumor microenvironment. Front Oncol. 2014; 4:62. [PubMed: 24734219]

37. Catteau X, Simon P, Noel JC. Myofibroblastic stromal reaction and lymph node status in invasive breast carcinoma: possible role of the TGF-beta1/TGF-betaR1 pathway. BMC Cancer. 2014; 14:499. [PubMed: 25011545]

38. Lohr M, et al. Transforming growth factor-beta1 induces desmoplasia in an experimental model of human pancreatic carcinoma. Cancer Res. 2001; 61:550-5. [PubMed: 11212248]

39. Ronnov-Jessen L, Petersen OW. Induction of alpha-smooth muscle actin by transforming growth factor-beta 1 in quiescent human breast gland fibroblasts. Implications for myofibroblast generation in breast neoplasia. Lab Invest. 1993; 68:696-707. [PubMed: 8515656]

40. Kojima Y, et al. Autocrine TGF-beta and stromal cell-derived factor-1 (SDF-1) signaling drives the evolution of tumor-promoting mammary stromal myofibroblasts. Proc Natl Acad Sci U S A. 2010; 107:20009-14. [PubMed: 21041659]

41. Liu Y, et al. IL-13 induces connective tissue growth factor in rat hepatic stellate cells via TGF-betaindependent Smad signaling. J Immunol. 2011; 187:2814-23. [PubMed: 21804025]

42. Hellevik T, et al. Cancer-associated fibroblasts from human NSCLC survive ablative doses of radiation but their invasive capacity is reduced. Radiat Oncol. 2012; 7:59. [PubMed: 22500976]

43. Cordes N, Seidler J, Durzok R, Geinitz H, Brakebusch C. beta1-integrin-mediated signaling essentially contributes to cell survival after radiation-induced genotoxic injury. Oncogene. 2006; 25:1378-90. [PubMed: 16247454]

44. Hodkinson PS, et al. ECM overrides DNA damage-induced cell cycle arrest and apoptosis in smallcell lung cancer cells through beta1 integrin-dependent activation of PI3-kinase. Cell Death Differ. 2006; 13:1776-88. [PubMed: 16410797]

45. Park CC, Zhang HJ, Yao ES, Park CJ, Bissell MJ. Beta1 integrin inhibition dramatically enhances radiotherapy efficacy in human breast cancer xenografts. Cancer Res. 2008; 68:4398-405. [PubMed: 18519702]

46. Mantoni TS, Lunardi S, Al-Assar O, Masamune A, Brunner TB. Pancreatic stellate cells radioprotect pancreatic cancer cells through beta1-integrin signaling. Cancer Res. 2011; 71:34538. [PubMed: 21558392] 
47. Carracedo S, et al. The fibroblast integrin alpha11beta1 is induced in a mechanosensitive manner involving activin A and regulates myofibroblast differentiation. J Biol Chem. 2010; 285:10434-45. [PubMed: 20129924]

48. Puthawala K, et al. Inhibition of integrin alpha(v)beta6, an activator of latent transforming growth factor-beta, prevents radiation-induced lung fibrosis. Am J Respir Crit Care Med. 2008; 177:8290. [PubMed: 17916808]

49. Dunn GP, Old LJ, Schreiber RD. The three Es of cancer immunoediting. Annu Rev Immunol. 2004; 22:329-60. [PubMed: 15032581]

50. Hanahan D, Weinberg RA. Hallmarks of cancer: the next generation. Cell. 2011; 144:646-74. [PubMed: 21376230]

51. Philip M, Rowley DA, Schreiber H. Inflammation as a tumor promoter in cancer induction. Semin Cancer Biol. 2004; 14:433-9. [PubMed: 15489136]

52. Li Q, Withoff S, Verma IM. Inflammation-associated cancer: NF-kappaB is the lynchpin. Trends Immunol. 2005; 26:318-25. [PubMed: 15922948]

53. Lin WW, Karin M. A cytokine-mediated link between innate immunity, inflammation, and cancer. J Clin Invest. 2007; 117:1175-83. [PubMed: 17476347]

54. Hiniker SM, et al. A systemic complete response of metastatic melanoma to local radiation and immunotherapy. Transl Oncol. 2012; 5:404-7. [PubMed: 23323154]

55. Harris TJ, et al. Radiotherapy augments the immune response to prostate cancer in a timedependent manner. Prostate. 2008; 68:1319-29. [PubMed: 18561247]

56. Laoui D, Van Overmeire E, De Baetselier P, Van Ginderachter JA, Raes G. Functional Relationship between Tumor-Associated Macrophages and Macrophage Colony-Stimulating Factor as Contributors to Cancer Progression. Front Immunol. 2014; 5:489. [PubMed: 25339957]

57. Kachikwu EL, et al. Radiation enhances regulatory $\mathrm{T}$ cell representation. Int J Radiat Oncol Biol Phys. 2011; 81:1128-35. [PubMed: 21093169]

58. Qu Y, et al. Gamma-ray resistance of regulatory CD4+CD25+Foxp3+ T cells in mice. Radiat Res. 2010; 173:148-57. [PubMed: 20095846]

59. Schaue D, McBride WH. Links between innate immunity and normal tissue radiobiology. Radiat Res. 2010; 173:406-17. [PubMed: 20334512]

60. Ozsoy HZ, Sivasubramanian N, Wieder ED, Pedersen S, Mann DL. Oxidative stress promotes ligand-independent and enhanced ligand-dependent tumor necrosis factor receptor signaling. $\mathrm{J}$ Biol Chem. 2008; 283:23419-28. [PubMed: 18544535]

61. Takeuchi O, Akira S. Pattern recognition receptors and inflammation. Cell. 2010; 140:805-20. [PubMed: 20303872]

62. Martins I, et al. Restoration of the immunogenicity of cisplatin-induced cancer cell death by endoplasmic reticulum stress. Oncogene. 2011; 30:1147-58. [PubMed: 21151176]

63. Krysko DV, et al. Immunogenic cell death and DAMPs in cancer therapy. Nat Rev Cancer. 2012; 12:860-75. [PubMed: 23151605]

64. Apetoh L, et al. Toll-like receptor 4-dependent contribution of the immune system to anticancer chemotherapy and radiotherapy. Nat Med. 2007; 13:1050-9. [PubMed: 17704786] [This paper explores explores the immunogenic response to HMGB1 release by dying tumour cells by the PRR TLR4, expressed on dendritic cells, after chemotherapy or radiotherapy. It demonstrates the important role of PRR DAMP signalling in efficient dendritic cell activation and antigen cross presentation.]

65. Qureshi OS, et al. Trans-endocytosis of CD80 and CD86: a molecular basis for the cell-extrinsic function of CTLA-4. Science. 2011; 332:600-3. [PubMed: 21474713] [This study explores the immunoregulatory actions of CTLA-4 against stimulation of CD28 by CD80 and CD86 (B7.1 and B7.2) in vitro and in vivo and therefore provides a biological basis for the efficacy of anti-CTLA-4 therapy in cancer treatments.]

66. Meng Y, et al. Ad.Egr-TNF and local ionizing radiation suppress metastases by interferon-betadependent activation of antigen-specific CD8+ T cells. Mol Ther. 2010; 18:912-20. [PubMed: 20197756]

67. Matsumura S, et al. Radiation-induced CXCL16 release by breast cancer cells attracts effector T cells. J Immunol. 2008; 181:3099-107. [PubMed: 18713980] 
68. Burnette BC, et al. The efficacy of radiotherapy relies upon induction of type i interferondependent innate and adaptive immunity. Cancer Res. 2011; 71:2488-96. [PubMed: 21300764]

69. Gupta A, et al. Radiotherapy promotes tumor-specific effector CD8+ T cells via dendritic cell activation. J Immunol. 2012; 189:558-66. [PubMed: 22685313] [This study examines the importance of dendritic cell activation in generating an effective CD8+ T-cell response after radiotherapy.]

70. Antoniades J, Brady LW, Lightfoot DA. Lymphangiographic demonstration of the abscopal effect in patients with malignant lymphomas. Int J Radiat Oncol Biol Phys. 1977; 2:141-7. [PubMed: 403163]

71. Ohba K, et al. Abscopal regression of hepatocellular carcinoma after radiotherapy for bone metastasis. Gut. 1998; 43:575-7. [PubMed: 9824589]

72. Wersall PJ, et al. Regression of non-irradiated metastases after extracranial stereotactic radiotherapy in metastatic renal cell carcinoma. Acta Oncol. 2006; 45:493-7. [PubMed: 16760190]

73. Okuma K, Yamashita H, Niibe Y, Hayakawa K, Nakagawa K. Abscopal effect of radiation on lung metastases of hepatocellular carcinoma: a case report. J Med Case Rep. 2011; 5:111. [PubMed: 21418591]

74. Postow MA, et al. Immunologic correlates of the abscopal effect in a patient with melanoma. $\mathrm{N}$ Engl J Med. 2012; 366:925-31. [PubMed: 22397654] [This case report demonstrates the abscopal effect with the combination of high fraction radiotherapy and anti-CTLA-4 immunotherapy in metastatic melanoma leading to regression of metastases throughout the patient. They also identify NY-ESO-1, changes in blood immune cells and increased antibody responses as possible biomarkers of this activity.]

75. Stamell EF, Wolchok JD, Gnjatic S, Lee NY, Brownell I. The abscopal effect associated with a systemic anti-melanoma immune response. Int J Radiat Oncol Biol Phys. 2013; 85:293-5. [PubMed: 22560555]

76. Harris AL. Hypoxia--a key regulatory factor in tumour growth. Nat Rev Cancer. 2002; 2:38-47. [PubMed: 11902584]

77. Overgaard J. Hypoxic modification of radiotherapy in squamous cell carcinoma of the head and neck--a systematic review and meta-analysis. Radiother Oncol. 2011; 100:22-32. [PubMed: 21511351] [This reference is a comprehensive review of the importance of tumour hypoxia for radiotherapy outcome and the current methods being trialed to modify hypoxia during radiotherapy for HNSCC patients.]

78. Vaupel P, Kallinowski F, Okunieff P. Blood flow, oxygen and nutrient supply, and metabolic microenvironment of human tumors: a review. Cancer Res. 1989; 49:6449-65. [PubMed: 2684393]

79. Brown JM. Evidence for acutely hypoxic cells in mouse tumours, and a possible mechanism of reoxygenation. Br J Radiol. 1979; 52:650-6. [PubMed: 486895]

80. Dewhirst MW, et al. Microvascular studies on the origins of perfusion-limited hypoxia. Br J Cancer Suppl. 1996; 27:S247-51. [PubMed: 8763890]

81. Harada H. How can we overcome tumor hypoxia in radiation therapy? J Radiat Res. 2011; 52:54556. [PubMed: 21952313]

82. Semenza GL. Intratumoral hypoxia, radiation resistance, and HIF-1. Cancer Cell. 2004; 5:405-6. [PubMed: 15144945]

83. Brizel DM, Sibley GS, Prosnitz LR, Scher RL, Dewhirst MW. Tumor hypoxia adversely affects the prognosis of carcinoma of the head and neck. Int J Radiat Oncol Biol Phys. 1997; 38:285-9. [PubMed: 9226314]

84. Yoshimura M, Itasaka S, Harada H, Hiraoka M. Microenvironment and radiation therapy. Biomed Res Int. 2013; 2013:685308. [PubMed: 23509762]

85. Janssens GO, et al. Improved recurrence-free survival with ARCON for anemic patients with laryngeal cancer. Clin Cancer Res. 2014; 20:1345-54. [PubMed: 24452791]

86. Hoskin P, Rojas A, Saunders M. Accelerated radiotherapy, carbogen, and nicotinamide (ARCON) in the treatment of advanced bladder cancer: mature results of a Phase II nonrandomized study. Int J Radiat Oncol Biol Phys. 2009; 73:1425-31. [PubMed: 19036531] 
87. Janssens GO, et al. Accelerated radiotherapy with carbogen and nicotinamide for laryngeal cancer: results of a phase III randomized trial. J Clin Oncol. 2012; 30:1777-83. [PubMed: 22508814]

88. Baillet F, Housset M, Dessard-Diana B, Boisserie G. Positive clinical experience with misonidazole in brachytherapy and external radiotherapy. Int J Radiat Oncol Biol Phys. 1989; 16:1073-5. [PubMed: 2703387]

89. Minsky BD, Leibel SA. The treatment of hepatic metastases from colorectal cancer with radiation therapy alone or combined with chemotherapy or misonidazole. Cancer Treat Rev. 1989; 16:2139. [PubMed: 2700316]

90. Simpson JR, et al. Radiation therapy alone or combined with misonidazole in the treatment of locally advanced non-oat cell lung cancer: report of an RTOG prospective randomized trial. Int J Radiat Oncol Biol Phys. 1989; 16:1483-91. [PubMed: 2542197]

91. Nishimura Y, et al. Phase I/II trial of sequential chemoradiotherapy using a novel hypoxic cell radiosensitizer, doranidazole (PR-350), in patients with locally advanced non-small-cell lung Cancer (WJTOG-0002). Int J Radiat Oncol Biol Phys. 2007; 69:786-92. [PubMed: 17512126]

92. Overgaard J, et al. A randomized double-blind phase III study of nimorazole as a hypoxic radiosensitizer of primary radiotherapy in supraglottic larynx and pharynx carcinoma. Results of the Danish Head and Neck Cancer Study (DAHANCA) Protocol 5-85. Radiother Oncol. 1998; 46:135-46. [PubMed: 9510041]

93. Thomson D, et al. NIMRAD - a phase III trial to investigate the use of nimorazole hypoxia modification with intensity-modulated radiotherapy in head and neck cancer. Clin Oncol (R Coll Radiol). 2014; 26:344-7. [PubMed: 24685344]

94. Prasad P, et al. Multifunctional albumin- $\mathrm{MnO}(2)$ nanoparticles modulate solid tumor microenvironment by attenuating hypoxia, acidosis, vascular endothelial growth factor and enhance radiation response. ACS Nano. 2014; 8:3202-12. [PubMed: 24702320] [This reference introduces the most recent attempt to modify tumour hypoxia using albumin- $\mathrm{MnO}_{2}$ nanoparticles, which increase tumour oxygenation in hypoxic regions. This treatment enhanced radiotherapy response of breast cancer.]

95. Moeller BJ, Cao Y, Li CY, Dewhirst MW. Radiation activates HIF-1 to regulate vascular radiosensitivity in tumors: role of reoxygenation, free radicals, and stress granules. Cancer Cell. 2004; 5:429-41. [PubMed: 15144951] [This reference demonstrates that radiotherapymediated tumour reoxygenation stabilises HIF-1 leading to enhanced cytokine secretion and endothelial cell radioresistance.]

96. Aebersold DM, et al. Expression of hypoxia-inducible factor-1alpha: a novel predictive and prognostic parameter in the radiotherapy of oropharyngeal cancer. Cancer Res. 2001; 61:2911-6. [PubMed: 11306467]

97. Koukourakis MI, et al. Hypoxia-inducible factor (HIF1A and HIF2A), angiogenesis, and chemoradiotherapy outcome of squamous cell head-and-neck cancer. Int J Radiat Oncol Biol Phys. 2002; 53:1192-202. [PubMed: 12128120]

98. Koukourakis MI, et al. Endogenous markers of two separate hypoxia response pathways (hypoxia inducible factor 2 alpha and carbonic anhydrase 9) are associated with radiotherapy failure in head and neck cancer patients recruited in the CHART randomized trial. J Clin Oncol. 2006; 24:727-35. [PubMed: 16418497]

99. Lee K, et al. Acriflavine inhibits HIF-1 dimerization, tumor growth, and vascularization. Proc Natl Acad Sci U S A. 2009; 106:17910-5. [PubMed: 19805192]

100. Harada H, et al. Treatment regimen determines whether an HIF-1 inhibitor enhances or inhibits the effect of radiation therapy. Br J Cancer. 2009; 100:747-57. [PubMed: 19223896]

101. Riedel K, et al. Abrogation of TGF-beta by antisense oligonucleotides modulates expression of VEGF and increases angiogenic potential in isolated fibroblasts from radiated skin. Int J Mol Med. 2008; 22:473-80. [PubMed: 18813854]

102. Goumans MJ, et al. Balancing the activation state of the endothelium via two distinct TGF-beta type I receptors. EMBO J. 2002; 21:1743-53. [PubMed: 11927558]

103. Carmeliet P, Jain RK. Principles and mechanisms of vessel normalization for cancer and other angiogenic diseases. Nat Rev Drug Discov. 2011; 10:417-27. [PubMed: 21629292] 
104. Ferrara N. VEGF and the quest for tumour angiogenesis factors. Nat Rev Cancer. 2002; 2:795803. [PubMed: 12360282]

105. Goel S, et al. Normalization of the vasculature for treatment of cancer and other diseases. Physiol Rev. 2011; 91:1071-121. [PubMed: 21742796]

106. Jain RK. Normalization of tumor vasculature: an emerging concept in antiangiogenic therapy. Science. 2005; 307:58-62. [PubMed: 15637262] [This reference reviews emerging evidence at the time that certain anti-angiogenic agents can normalise the abnormal tumour vessels to enable better oxygen and drug delivery, rather than completely destroying the tumour vasculature as previously thought.]

107. Fokas E, et al. Dual inhibition of the PI3K/mTOR pathway increases tumor radiosensitivity by normalizing tumor vasculature. Cancer Res. 2012; 72:239-48. [PubMed: 22108822]

108. Dings RP, et al. Scheduling of radiation with angiogenesis inhibitors anginex and Avastin improves therapeutic outcome via vessel normalization. Clin Cancer Res. 2007; 13:3395-402. [PubMed: 17545548] [This reference demonstrates the use of anti-angiogenics in vessel normalisation and the importance of scheduling radiotherapy to fall within the "tumour oxygenation window"]

109. McGee MC, et al. Improved intratumoral oxygenation through vascular normalization increases glioma sensitivity to ionizing radiation. Int J Radiat Oncol Biol Phys. 2010; 76:1537-45. [PubMed: 20338480]

110. Carmeliet P, Jain RK. Angiogenesis in cancer and other diseases. Nature. 2000; 407:249-57. [PubMed: 11001068]

111. Lund EL, Bastholm L, Kristjansen PE. Therapeutic synergy of TNP-470 and ionizing radiation: effects on tumor growth, vessel morphology, and angiogenesis in human glioblastoma multiforme xenografts. Clin Cancer Res. 2000; 6:971-8. [PubMed: 10741723]

112. Teicher BA, Emi Y, Kakeji Y, Northey D. TNP-470/minocycline/cytotoxic therapy: a systems approach to cancer therapy. Eur J Cancer. 1996; 32A:2461-6. [PubMed: 9059334]

113. Teicher BA, et al. Potentiation of cytotoxic therapies by TNP-470 and minocycline in mice bearing EMT-6 mammary carcinoma. Breast Cancer Res Treat. 1995; 36:227-36. [PubMed: 8534870]

114. Ling Y, et al. Endostar, a novel recombinant human endostatin, exerts antiangiogenic effect via blocking VEGF-induced tyrosine phosphorylation of KDR/Flk-1 of endothelial cells. Biochem Biophys Res Commun. 2007; 361:79-84. [PubMed: 17644065]

115. Wu Y, et al. Endostar combined with radiotherapy increases radiation sensitivity by decreasing the expression of TGF-beta1, HIF-1alpha and bFGF. Exp Ther Med. 2014; 7:911-916. [PubMed: 24669250]

116. Zhou J, et al. Antitumor activity of Endostar combined with radiation against human nasopharyngeal carcinoma in mouse xenograft models. Oncol Lett. 2012; 4:976-980. [PubMed: 23162635]

117. Brown JM. Vasculogenesis: a crucial player in the resistance of solid tumours to radiotherapy. $\mathrm{Br}$ J Radiol. 2014; 87:20130686. [PubMed: 24338942]

118. Burrell K, Singh S, Jalali S, Hill RP, Zadeh G. VEGF regulates region-specific localization of perivascular bone marrow-derived cells in glioblastoma. Cancer Res. 2014; 74:3727-39. [PubMed: 24820020]

119. Abdollahi A, et al. Inhibition of alpha(v)beta3 integrin survival signaling enhances antiangiogenic and antitumor effects of radiotherapy. Clin Cancer Res. 2005; 11:6270-9. [PubMed: 16144931]

120. Nabors LB, et al. A safety run-in and randomized phase 2 study of cilengitide combined with chemoradiation for newly diagnosed glioblastoma (NABTT 0306). Cancer. 2012; 118:5601-7. [PubMed: 22517399]

121. Stupp R, et al. Cilengitide combined with standard treatment for patients with newly diagnosed glioblastoma with methylated MGMT promoter (CENTRIC EORTC 26071-22072 study): a multicentre, randomised, open-label, phase 3 trial. Lancet Oncol. 2014; 15:1100-8. [PubMed: 25163906] 
122. Gutheil JC, et al. Targeted antiangiogenic therapy for cancer using Vitaxin: a humanized monoclonal antibody to the integrin alphavbeta3. Clin Cancer Res. 2000; 6:3056-61. [PubMed: 10955784]

123. Kuwada SK. Drug evaluation: Volociximab, an angiogenesis-inhibiting chimeric monoclonal antibody. Curr Opin Mol Ther. 2007; 9:92-8. [PubMed: 17330407]

124. Barkan D, Chambers AF. beta1-integrin: a potential therapeutic target in the battle against cancer recurrence. Clin Cancer Res. 2011; 17:7219-23. [PubMed: 21900388]

125. Multhoff G, Radons J. Radiation, inflammation, and immune responses in cancer. Front Oncol. 2012; 2:58. [PubMed: 22675673]

126. Barcellos-Hoff MH, Derynck R, Tsang ML, Weatherbee JA. Transforming growth factor-beta activation in irradiated murine mammary gland. J Clin Invest. 1994; 93:892-9. [PubMed: 8113421]

127. Dancea HC, Shareef MM, Ahmed MM. Role of Radiation-induced TGF-beta Signaling in Cancer Therapy. Mol Cell Pharmacol. 2009; 1:44-56. [PubMed: 20336170]

128. Biswas S, et al. Inhibition of TGF-beta with neutralizing antibodies prevents radiation-induced acceleration of metastatic cancer progression. J Clin Invest. 2007; 117:1305-13. [PubMed: 17415413] [This reference implicates TGF- $\beta$ in post-radiotherapy induction of metastasis and provides a rationale for combining TGF- $\beta$ inhibitors with radiotherapy to prevent cancer progression.]

129. Bouquet $F$, et al. TGFbeta1 inhibition increases the radiosensitivity of breast cancer cells in vitro and promotes tumor control by radiation in vivo. Clin Cancer Res. 2011; 17:6754-65. [PubMed: 22028490]

130. Neuzillet C, et al. Targeting the TGFbeta pathway for cancer therapy. Pharmacology and Therapeutics. 2014 In Press.

131. Medicherla S, et al. Antitumor activity of TGF-beta inhibitor is dependent on the microenvironment. Anticancer Res. 2007; 27:4149-57. [PubMed: 18229422]

132. Cui JJ. Targeting receptor tyrosine kinase MET in cancer: small molecule inhibitors and clinical progress. J Med Chem. 2014; 57:4427-53. [PubMed: 24320965]

133. De Bacco F, et al. Induction of MET by ionizing radiation and its role in radioresistance and invasive growth of cancer. J Natl Cancer Inst. 2011; 103:645-61. [PubMed: 21464397]

134. Ohuchida K, et al. Radiation to stromal fibroblasts increases invasiveness of pancreatic cancer cells through tumor-stromal interactions. Cancer Res. 2004; 64:3215-22. [PubMed: 15126362] [This reference presents the findings that irradiated fibroblasts can increase the invasiveness of pancreatic cancer cells. This increased invasion can be abrogated through cMet inhibition using a specific HGF antagonist.]

135. Cokgor I, et al. Phase I trial results of iodine-131-labeled antitenascin monoclonal antibody 81C6 treatment of patients with newly diagnosed malignant gliomas. J Clin Oncol. 2000; 18:3862-72. [PubMed: 11078500]

136. Reardon DA, et al. Phase II trial of murine (131)I-labeled antitenascin monoclonal antibody 81C6 administered into surgically created resection cavities of patients with newly diagnosed malignant gliomas. J Clin Oncol. 2002; 20:1389-97. [PubMed: 11870184]

137. Reardon DA, et al. A pilot study: 131I-antitenascin monoclonal antibody $81 \mathrm{c} 6$ to deliver a 44-Gy resection cavity boost. Neuro Oncol. 2008; 10:182-9. [PubMed: 18287339]

138. Distler JH, Distler O. Tyrosine kinase inhibitors for the treatment of fibrotic diseases such as systemic sclerosis: towards molecular targeted therapies. Ann Rheum Dis. 2010; 69 Suppl 1:i4851. [PubMed: 19995744]

139. Antoniu SA. Nintedanib (BIBF 1120) for IPF: a tomorrow therapy? Multidiscip Respir Med. 2012; 7:41. [PubMed: 23146151]

140. Chaudhary NI, et al. Inhibition of PDGF, VEGF and FGF signalling attenuates fibrosis. Eur Respir J. 2007; 29:976-85. [PubMed: 17301095]

141. Omenetti A, et al. Hedgehog signaling regulates epithelial-mesenchymal transition during biliary fibrosis in rodents and humans. J Clin Invest. 2008; 118:3331-42. [PubMed: 18802480]

142. Bailey JM, et al. Sonic hedgehog promotes desmoplasia in pancreatic cancer. Clin Cancer Res. 2008; 14:5995-6004. [PubMed: 18829478] 
143. Lee MJ, et al. Hedgehog pathway inhibitor saridegib (IPI-926) increases lifespan in a mouse medulloblastoma model. Proc Natl Acad Sci U S A. 2012; 109:7859-64. [PubMed: 22550175]

144. Rodon J, et al. A phase I, multicenter, open-label, first-in-human, dose-escalation study of the oral smoothened inhibitor Sonidegib (LDE225) in patients with advanced solid tumors. Clin Cancer Res. 2014; 20:1900-9. [PubMed: 24523439]

145. Sekulic A, et al. Efficacy and safety of vismodegib in advanced basal-cell carcinoma. N Engl J Med. 2012; 366:2171-9. [PubMed: 22670903]

146. Bayers S, Kapp DL, Beer KR, Slavin B. Treatment of margin positive basal cell carcinoma with vismodegib: case report and consideration of treatment options and their implications. J Drugs Dermatol. 2013; 12:s147-50. [PubMed: 24085060]

147. Leschey KH, Hines J, Singer JH, Hackett SF, Campochiaro PA. Inhibition of growth factor effects in retinal pigment epithelial cells. Invest Ophthalmol Vis Sci. 1991; 32:1770-8. [PubMed: 2032799]

148. McGeary RP, Bennett AJ, Tran QB, Cosgrove KL, Ross BP. Suramin: clinical uses and structureactivity relationships. Mini Rev Med Chem. 2008; 8:1384-94. [PubMed: 18991754]

149. Laterra JJ, et al. Suramin and radiotherapy in newly diagnosed glioblastoma: phase 2 NABTT CNS Consortium study. Neuro Oncol. 2004; 6:15-20. [PubMed: 14769135]

150. Tayel A, et al. Suramin inhibits hepatic tissue damage in hepatocellular carcinoma through deactivation of heparanase enzyme. Eur J Pharmacol. 2014; 728:151-60. [PubMed: 24530413]

151. Vlodavsky I, et al. Significance of heparanase in cancer and inflammation. Cancer Microenviron. 2012; 5:115-32. [PubMed: 21811836]

152. Meirovitz A, et al. Role of heparanase in radiation-enhanced invasiveness of pancreatic carcinoma. Cancer Res. 2011; 71:2772-80. [PubMed: 21447736] [This reference reports that radiotherapy-induced heparanase up-regulation increases the invasion of pancreatic cancer cells. Inhibition of heparanase using SST0001 in combination with radiotherapy successfully attenuated the spread of orthotopic pancreatic tumours in vivo.]

153. Dredge K, et al. PG545, a dual heparanase and angiogenesis inhibitor, induces potent anti-tumour and anti-metastatic efficacy in preclinical models. Br J Cancer. 2011; 104:635-42. [PubMed: 21285983]

154. Liu CJ, et al. Adjuvant heparanase inhibitor PI-88 therapy for hepatocellular carcinoma recurrence. World J Gastroenterol. 2014; 20:11384-93. [PubMed: 25170226]

155. Hammond E, Handley P, Dredge K, Bytheway I. Mechanisms of heparanase inhibition by the heparan sulfate mimetic PG545 and three structural analogues. FEBS Open Bio. 2013; 3:346-51.

156. Junttila MR, de Sauvage FJ. Influence of tumour micro-environment heterogeneity on therapeutic response. Nature. 2013; 501:346-54. [PubMed: 24048067]

157. Badiga AV, et al. MMP-2 siRNA inhibits radiation-enhanced invasiveness in glioma cells. PLoS One. 2011; 6:e20614. [PubMed: 21698233]

158. Kaliski A, et al. Angiogenesis and tumor growth inhibition by a matrix metalloproteinase inhibitor targeting radiation-induced invasion. Mol Cancer Ther. 2005; 4:1717-28. [PubMed: 16275993]

159. Qian LW, et al. Radiation-induced increase in invasive potential of human pancreatic cancer cells and its blockade by a matrix metalloproteinase inhibitor, CGS27023. Clin Cancer Res. 2002; 8:1223-7. [PubMed: 11948136]

160. Takahashi M, et al. In vivo glioma growth requires host-derived matrix metalloproteinase 2 for maintenance of angioarchitecture. Pharmacol Res. 2002; 46:155-63. [PubMed: 12220955]

161. Ozdemir BC, et al. Depletion of carcinoma-associated fibroblasts and fibrosis induces immunosuppression and accelerates pancreas cancer with reduced survival. Cancer Cell. 2014; 25:719-34. [PubMed: 24856586] [This reference demonstrates a novel role for CAFs in the TME of pancreatic cancer. In contrast to previous beliefs, depletion of CAFs in a pancreatic cancer model led to disease progression. Moreover, PDAC patients with fewer myofibroblasts were shown to have a worse prognosis.]

162. Huang Q, et al. Caspase 3-mediated stimulation of tumor cell repopulation during cancer radiotherapy. Nat Med. 2011; 17:860-6. [PubMed: 21725296] [This study identifies caspase 3, 
involved in apoptosis after exposure to ionizing radiation, as an important component in repopulation signalling and tumour resistance.]

163. Mantovani A, Romero P, Palucka AK, Marincola FM. Tumour immunity: effector response to tumour and role of the microenvironment. Lancet. 2008; 371:771-83. [PubMed: 18275997]

164. Finkelstein SE, et al. Combination of external beam radiotherapy (EBRT) with intratumoral injection of dendritic cells as neo-adjuvant treatment of high-risk soft tissue sarcoma patients. Int J Radiat Oncol Biol Phys. 2012; 82:924-32. [PubMed: 21398051]

165. Roses RE, Datta J, Czerniecki BJ. Radiation as immunomodulator: implications for dendritic cellbased immunotherapy. Radiat Res. 2014; 182:211-8. [PubMed: 24992163]

166. Dewan MZ, et al. Synergy of topical toll-like receptor 7 agonist with radiation and low-dose cyclophosphamide in a mouse model of cutaneous breast cancer. Clin Cancer Res. 2012; 18:6668-78. [PubMed: 23048078] [This study explores different fractionation of radiotherapy in combination with anti-CTLA-4 in a murine model demonstrating an optimal fractionation at around $24 \mathrm{~Gy}$ in 3 doses.]

167. Czerniecki BJ, et al. Targeting HER-2/neu in early breast cancer development using dendritic cells with staged interleukin-12 burst secretion. Cancer Res. 2007; 67:1842-52. [PubMed: 17293384]

168. Formenti S, et al. Pilot Trial of Radiation Therapy and GM-CSF in Metastatic Cancer: Abscopal Responses. International Journal of Radiation Oncology Biology Physics. 2012; 84:S178-S178.

169. Hodi FS, et al. Improved survival with ipilimumab in patients with metastatic melanoma. N Engl J Med. 2010; 363:711-23. [PubMed: 20525992]

170. Robert $\mathrm{C}$, et al. Ipilimumab plus dacarbazine for previously untreated metastatic melanoma. $\mathrm{N}$ Engl J Med. 2011; 364:2517-26. [PubMed: 21639810]

171. Dewan MZ, et al. Fractionated but not single-dose radiotherapy induces an immune-mediated abscopal effect when combined with anti-CTLA-4 antibody. Clin Cancer Res. 2009; 15:5379-88. [PubMed: 19706802]

172. Gough MJ, et al. Adjuvant therapy with agonistic antibodies to CD134 (OX40) increases local control after surgical or radiation therapy of cancer in mice. J Immunother. 2010; 33:798-809. [PubMed: 20842057]

173. de la Cruz-Merino L, et al. Radiation for Awakening the Dormant Immune System, a Promising Challenge to be Explored. Front Immunol. 2014; 5:102. [PubMed: 24672524]

174. Melero I, Hervas-Stubbs S, Glennie M, Pardoll DM, Chen L. Immunostimulatory monoclonal antibodies for cancer therapy. Nat Rev Cancer. 2007; 7:95-106. [PubMed: 17251916]

175. Wherry EJ, et al. Molecular signature of CD8+ T cell exhaustion during chronic viral infection. Immunity. 2007; 27:670-84. [PubMed: 17950003]

176. Baitsch L, et al. Exhaustion of tumor-specific CD8(+) T cells in metastases from melanoma patients. J Clin Invest. 2011; 121:2350-60. [PubMed: 21555851]

177. Sakuishi K, et al. Targeting Tim-3 and PD-1 pathways to reverse T cell exhaustion and restore anti-tumor immunity. J Exp Med. 2010; 207:2187-94. [PubMed: 20819927] [This study looks at the reversal of T-cell exhaustion by combined targeting of PD-1 and TIM3 receptors as a means of increasing tumour immunity. It is likely that similar combinations in conjunction with radiotherapy could prove effective as future cancer treatments.]

178. Matsuzaki J, et al. Tumor-infiltrating NY-ESO-1 specific CD8+ T cells are negatively regulated by LAG-3 and PD-1 in human ovarian cancer. Proc Natl Acad Sci U S A. 2010; 107:7875-80. [PubMed: 20385810]

179. Deng L, et al. Irradiation and anti-PD-L1 treatment synergistically promote antitumor immunity in mice. J Clin Invest. 2014; 124:687-95. [PubMed: 24382348] [This preclinical study demonstrates the effectiveness of targeting T-cell exhaustion pathways in combination with radiotherapy. There is also a potential synergistic effect with anti-CTLA-4 and other immunomodulatory therapies.]

180. Verbrugge I, et al. Radiotherapy increases the permissiveness of established mammary tumors to rejection by immunomodulatory antibodies. Cancer Res. 2012; 72:3163-74. [PubMed: 22570253] 
181. Marabelle A, Filatenkov A, Sagiv-Barfi I, Kohrt H. Radiotherapy and Toll-Like Receptor Agonists. Semin Radiat Oncol. 2015; 25:34-39. [PubMed: 25481264]

182. Russell SJ, Peng KW, Bell JC. Oncolytic virotherapy. Nat Biotechnol. 2012; 30:658-70. [PubMed: 22781695]

183. Prestwich RJ, et al. Oncolytic viruses: a novel form of immunotherapy. Expert Rev Anticancer Ther. 2008; 8:1581-8. [PubMed: 18925850]

184. Dai MH, et al. Oncolytic vaccinia virus in combination with radiation shows synergistic antitumor efficacy in pancreatic cancer. Cancer Lett. 2014; 344:282-90. [PubMed: 24321381]

185. Kyula JN, et al. Synergistic cytotoxicity of radiation and oncolytic Lister strain vaccinia in (V600D/E)BRAF mutant melanoma depends on JNK and TNF-alpha signaling. Oncogene. 2014; 33:1700-12. [PubMed: 23624923]

186. Harrington KJ, et al. Phase I/II study of oncolytic HSV GM-CSF in combination with radiotherapy and cisplatin in untreated stage III/IV squamous cell cancer of the head and neck. Clin Cancer Res. 2010; 16:4005-15. [PubMed: 20670951] [This study looks at using oncolytic virus with immunomodulation and radiotherapy/chemotherapy to treat resistant HNSCC demonstrating the combinatorial possibilities available with oncoviral therapy in treating resistant cancers.]

187. Miyamoto S, et al. Coxsackievirus B3 is an oncolytic virus with immunostimulatory properties that is active against lung adenocarcinoma. Cancer Res. 2012; 72:2609-21. [PubMed: 22461509]

188. Hu JC, et al. A phase I study of OncoVEXGM-CSF, a second-generation oncolytic herpes simplex virus expressing granulocyte macrophage colony-stimulating factor. Clin Cancer Res. 2006; 12:6737-47. [PubMed: 17121894]

189. Brown JM, Wilson WR. Exploiting tumour hypoxia in cancer treatment. Nat Rev Cancer. 2004; 4:437-47. [PubMed: 15170446]

190. Zeng J, et al. Anti-PD-1 blockade and stereotactic radiation produce long-term survival in mice with intracranial gliomas. Int J Radiat Oncol Biol Phys. 2013; 86:343-9. [PubMed: 23462419]

191. Demaria S, et al. Immune-mediated inhibition of metastases after treatment with local radiation and CTLA-4 blockade in a mouse model of breast cancer. Clin Cancer Res. 2005; 11:728-34. [PubMed: 15701862]

192. Chi KH, et al. Combination of conformal radiotherapy and intratumoral injection of adoptive dendritic cell immunotherapy in refractory hepatoma. J Immunother. 2005; 28:129-35. [PubMed: 15725956]

193. Gulley JL, et al. Combining a recombinant cancer vaccine with standard definitive radiotherapy in patients with localized prostate cancer. Clin Cancer Res. 2005; 11:3353-62. [PubMed: 15867235]

194. Kim YH, et al. Phase I trial of a Toll-like receptor 9 agonist, PF-3512676 (CPG 7909), in patients with treatment-refractory, cutaneous T-cell lymphoma. J Am Acad Dermatol. 2010; 63:975-83. [PubMed: 20888065]

195. Seung SK, et al. Phase 1 study of stereotactic body radiotherapy and interleukin-2--tumor and immunological responses. Sci Transl Med. 2012; 4:137ra74. 


\section{Box 1}

\section{Normal wound healing versus radiation fibrosis}

The normal phases of wound healing progress from the injurious stimulus to inflammation, proliferation and finally resolution. By contrast, radiation generates reactive oxygen species (ROS), DNA damage and inflammation as the early stimuli that mediate activation of a dysregulated proliferative phase. Unlike wound healing, radiation exerts a field effect on the vascular compartment. Endothelial dysfunction leads to a progressive vasculopathy characterised by impaired gaseous exchange and the development of tissue hypoxia, which drive an uncontrolled proliferative stage that replaces the normal proliferative phase of wound healing. This may represent a poorly coordinated haemostatic response aiming to preserve tissue oxygenation. The progressive and perpetuating (blue arrows represent positive feedback loops) proliferative phase prevents tissue resolution and results in the development of late adverse effects.

\section{Normal wound healing}
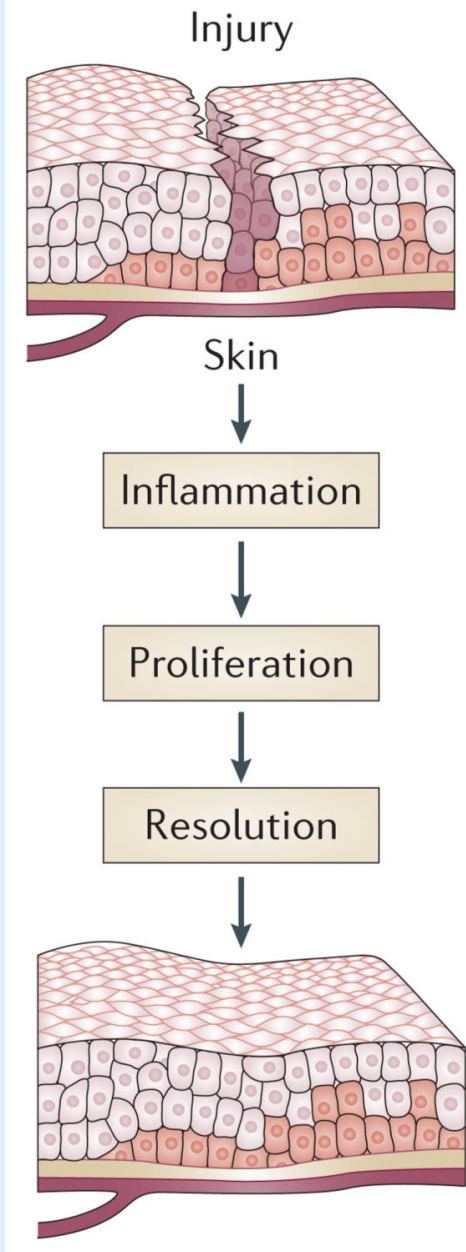

\section{Radiation-induced fibrosis}

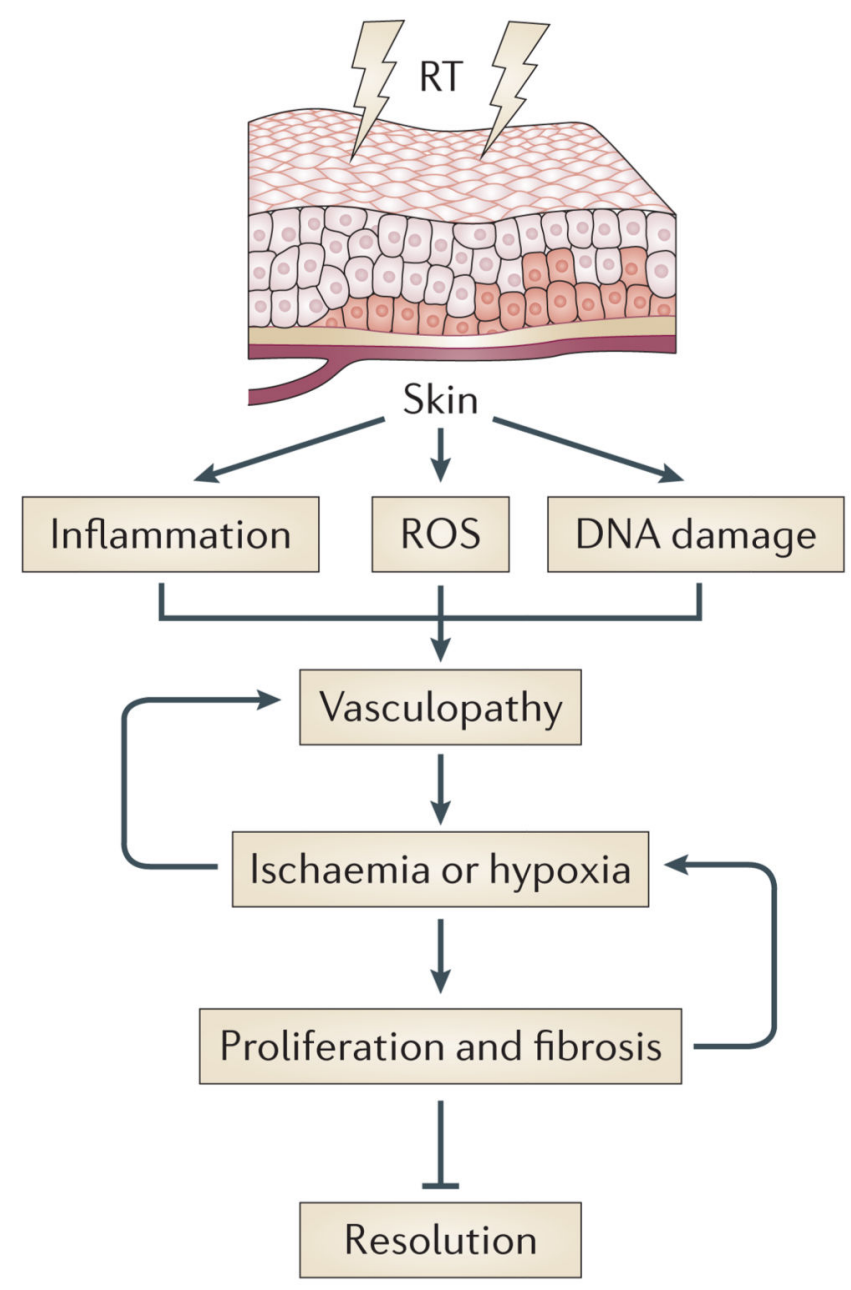




\section{Box 2}

\section{Hypoxia - mediated mechanisms of radioresistance in the tumour microenvironment (TME)}

a) Ionizing radiation produces DNA radicals (DNA •) which are usually fixed by $\mathrm{O}_{2}$ (in normoxic regions) and causes DNA damage that can lead to cell death if unrepaired. However, under hypoxia DNA damage is reduced (mainly by - SH containing compounds) leading to cell survival. Modified with permission from Ref 189.

b) HIF-1a is stabilised under hypoxic conditions leading to up-regulation of genes involved in cell survival. Radiotherapy causes tumour reoxygenation, an increase in reactive oxygen species (ROS), and contributes to HIF-1a stabilisation.

c) Hypoxia increases VEGF-A production leading to the formation of abnormal vessels, which also contribute to tumour hypoxia.

d) Vasculogenesis aids tumour recurrence following radiotherapy and can be driven by HIF-1a-mediated BMDC recruitment.

a
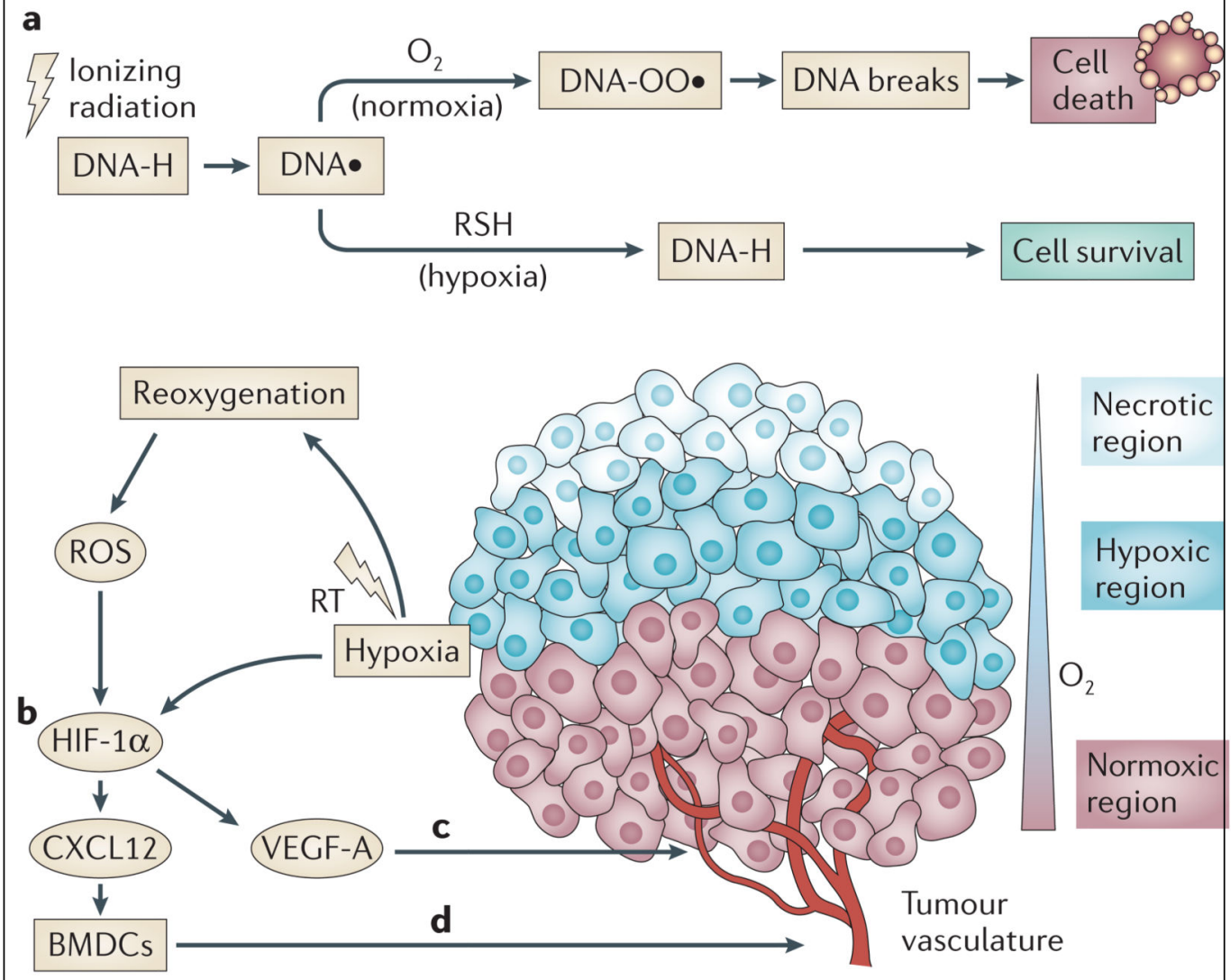


\section{Key points}

- $\quad$ Radiotherapy is a common treatment option for cancer patients. However, many aspects of the tumour microenvironment (TME) can render a tumour resistant to radiotherapy de novo or lead it to recur with a worse prognosis following therapy.

Normal tissue toxicity limits the dose of radiotherapy that can be delivered safely.

- $\quad$ Combination strategies are required in order to achieve better tumour control.

- $\quad$ Radiotherapy-mediated immunogenic cell death (ICD) can elicit an immune response, but anti-tumour immunity may be limited due to the presence of radioresistant suppressor cell types in the TME. Combining radiotherapy and immunomodulatory treatments may overcome adaptive immune suppression and has great promise both locally in the primary tumour and abscopally.

- Hypoxia plays a crucial role in radioresistance due to reduced oxygenmediated fixation of DNA damage and hypoxia induced factor-1a (HIF-1a)-mediated cell survival. Attempts to increase oxygen delivery, normalise tumour vessels, inhibit HIF-1a, and prevent the recruitment of bone marrow derived cells (BMDCs) required for vasculogenesis are all being tested to reduce tumour hypoxia, improve radiotherapy responses and prevent tumour recurrence after therapy.

Tumour irradiation induces a wound healing response characterised by inflammation, cancer-associated fibroblast (CAF) modulation and ECM remodelling, which may facilitate tumour recurrence. Targeting the initial inflammatory response may counteract attempts to boost the immune-mediated anti-tumour response following radiotherapy.

Therefore, reducing ECM remodelling by inhibiting growth factors, receptor kinases, or matrix enzymes may be more effective in preventing the post-irradiation stiffening of the TME that could facilitate tumour spread.

- $\quad$ Careful scheduling of tumour reoxygenation strategies with radiotherapy will be required to maximise tumour control. Subsequent inclusion of immunomodulatory and anti-fibrotic treatments should be considered to maximise therapeutic benefits and prevent postirradiation tumour recurrence and metastasis. 

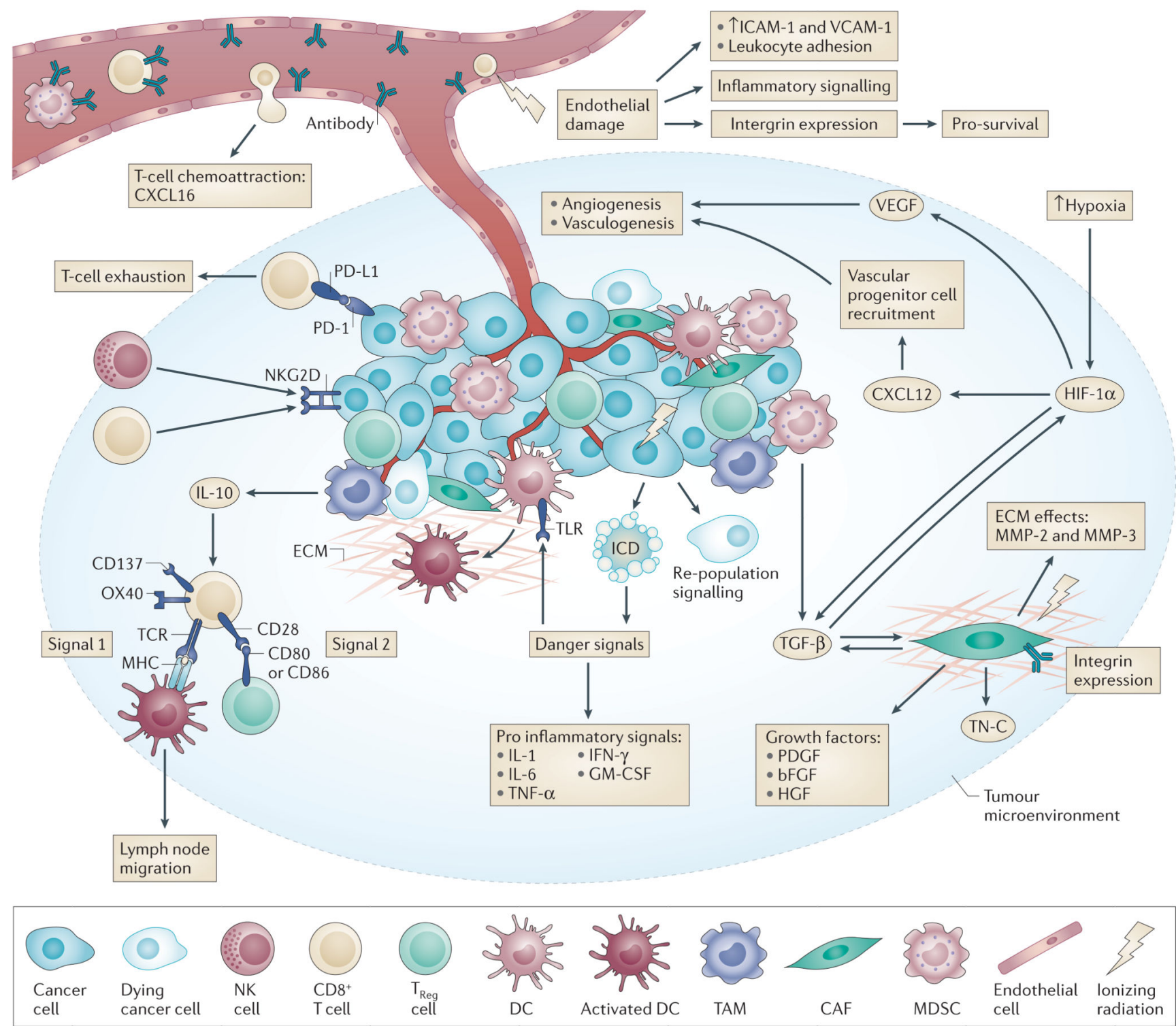

Figure 1. Radiation effects on the tumour microenvironment (TME)

Ionizing radiation damage leads to effects on numerous cell types within the TME. Tumour endothelial cells are sensitive to radiation, and their death initiates the inflammation cascade. Damage also leads to increased ICAM and VCAM expression and increased attraction of innate immune cells. Upregulation of integrins on endothelial cells leads to increased survival, which acts as a method of radioresistance. Vascular depletion potentiates the effects of hypoxia leading to HIF-1 signalling and to pro-angiogenic stimuli through VEGF and pro-vasculogenic stimuli through CXCL12. CAF activation following radiation leads to altered growth factor secretion and release of numerous modulators of the ECM and cytokines. TGF- $\beta$ signalling is complex and pleiotrophic — directly affecting tumour cells and CAFs, driving HIF-1 signalling and reducing the activation of T-cells and dendritic cells (DCs). Within the immune compartment, increased tumour cell antigen availability and increased antigen processing by higher mTOR levels combine with a DAMP-related TLR 
response and increased pro-inflammatory cytokine signalling to activate DCs and thus Tcells; activated DCs also migrate to proximal lymph nodes. This signalling is often still blocked by high $\mathrm{T}_{\text {reg }}$ CTLA-4 inhibition of co-stimulation within the TME. Whilst radiation also upregulates NKG2D signals on tumour cells which allow direct cytoxic effects by NK cells and CD8+ T-cells, other tumour escape mechanisms such as PD-L1 signalling and MDSC derived IL-10 immunosuppression remain intact. 


\begin{tabular}{c|c|c|c|c|c} 
Minutes & Hours & Days & Weeks & Months & Years \\
\hline & & Proliferative phase & Tissue remodelling phase
\end{tabular}

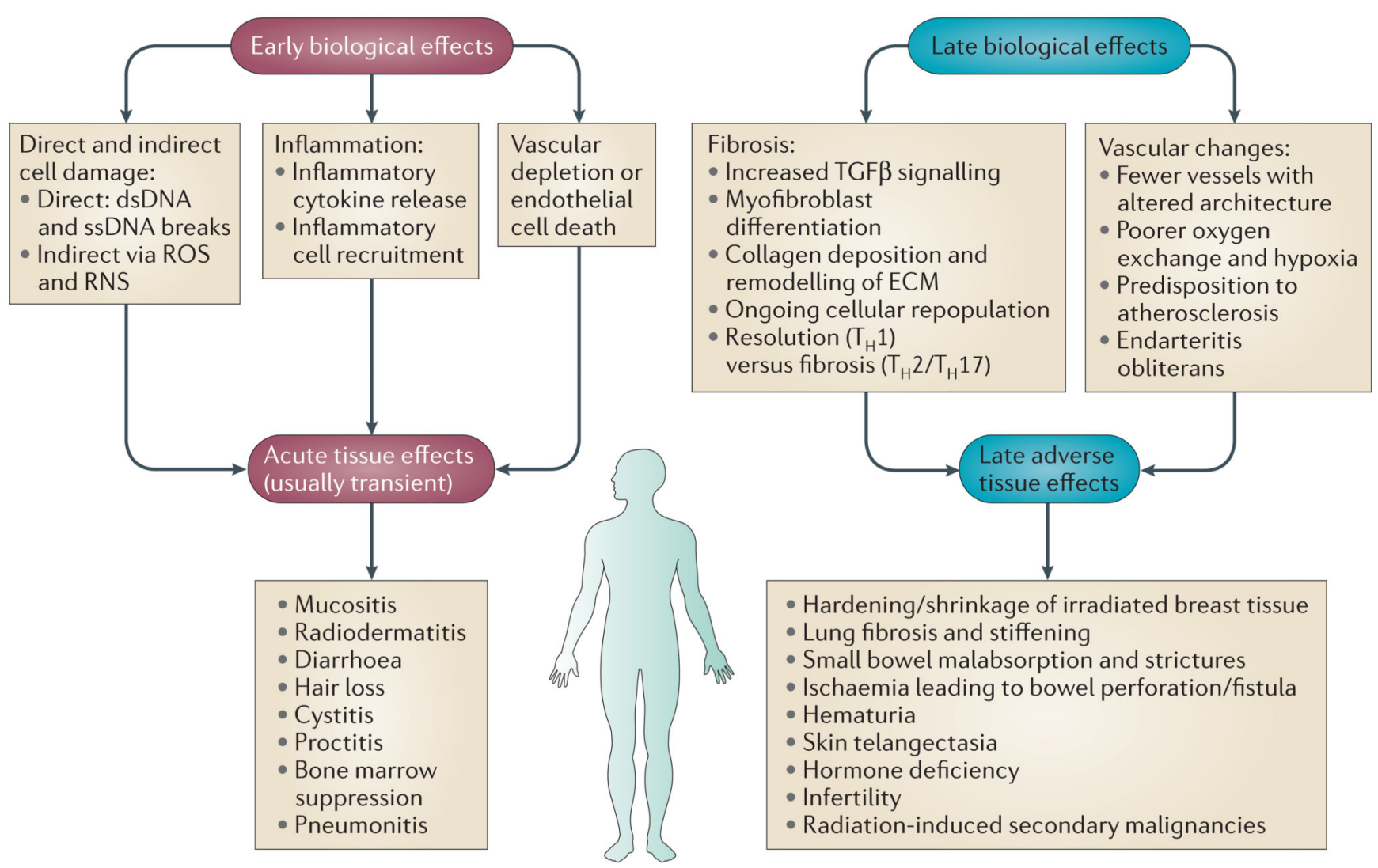

Figure 2. Biological effects and normal tissue toxicity after radiotherapy

Early biological events cause acute tissue effects, which are usually transient and normally resolve within three months of completing treatment. They also result in more protracted biological effects which can manifest in tissues as late biological effects and secondary malignancies. Higher radiation dose per fraction seems to increase the severity of late adverse effects. Abbreviations: dsDNA, double strand DNA; ECM, extracellular matrix; ssDNA, single strand DNA; TGF- $\beta$, transforming growth factor $\beta$; TH2/TH17, T-helper cells (classified by the interleukin they principally secrete). 


\section{a Immune cell death}

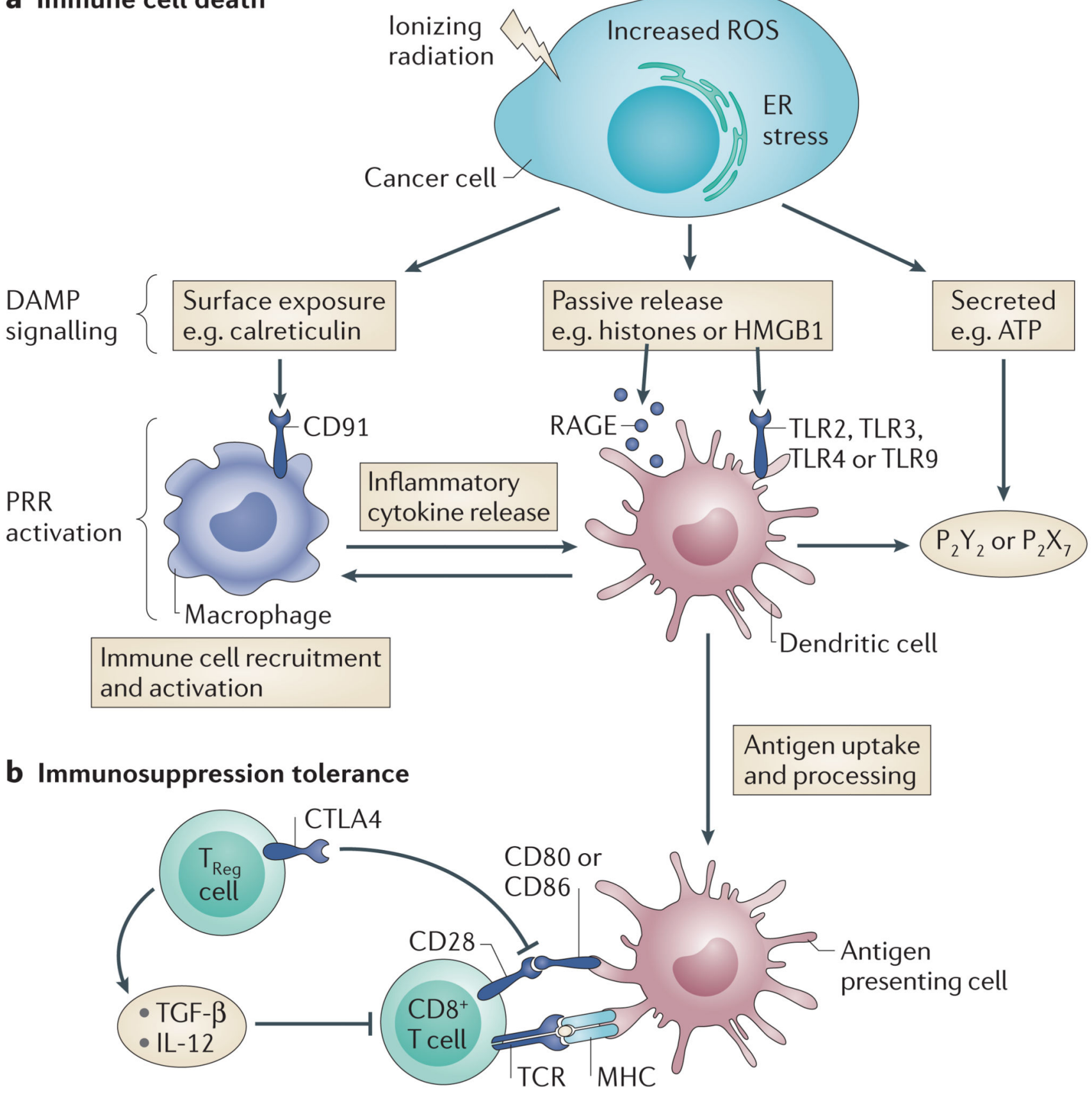

Figure 3. Immunogenic cell death (ICD) of cancer cells and immune tolerisation

a) Radiotherapy damage to cancer cells leads to cell stress mediated by reactive oxygen species (ROS) and endoplasmic reticulum (ER) stress; this in turn results in DAMP signalling. Three main types of DAMP signalling are now recognised - surface exposure, passive release and active secretion57. The degree of different DAMP release appears to vary with different types of cell stress so that cell stress, apoptosis and necrosis likely result in a different pattern of DAMP signalling. Multiple DAMP signal activation appears to be necessary to achieve effective ICD in cancer cells to cause an adaptive immune response. 
DAMP signals through multiple PRR types, e.g. HSP90 or calreticulin surface exposure leads to phagocytosis mediated by CD91 (expressed on a variety of innate immune cells); HGMB1 release activates TLR2 and TLR4 which in turn lead to MyD88 signalling, DC activation and increased production of inflammatory cytokines; ATP secretion activates purinergic receptors $\mathrm{P} 2 \mathrm{Y} 2$ and $\mathrm{P} 2 \mathrm{X} 7$ which have wide ranging immunostimulatory actions across DCs, NK cells, macrophages and T-cells. Effective ICD of cancer cells therefore increases the background inflammatory signalling and generates activated DCs to act as APCs.

b) Immune tolerisation [G]. APCs present processed antigen on MHCI receptors to CD8+ Tcells via their corresponding TCRs. Co- stimulation is required to achieve T-cell activation. This can be achieved by the interaction of CD80 (also known as B7.1) and CD86 (also known as B7.2) on the APC with CD28 on the CD8+ T-cell. $\mathrm{T}_{\text {reg }}$ cells express CTLA-4, which has a higher affinity for B7.1 and B7.2 than CD28 and thus effectively inactivates the co-stimulatory signal leading to ineffective T-cell activation. Overcoming this process with appropriate immunomodulation allows for effective exposure of cancer cells to the immune system and the exciting prospect of novel cancer treatments. 


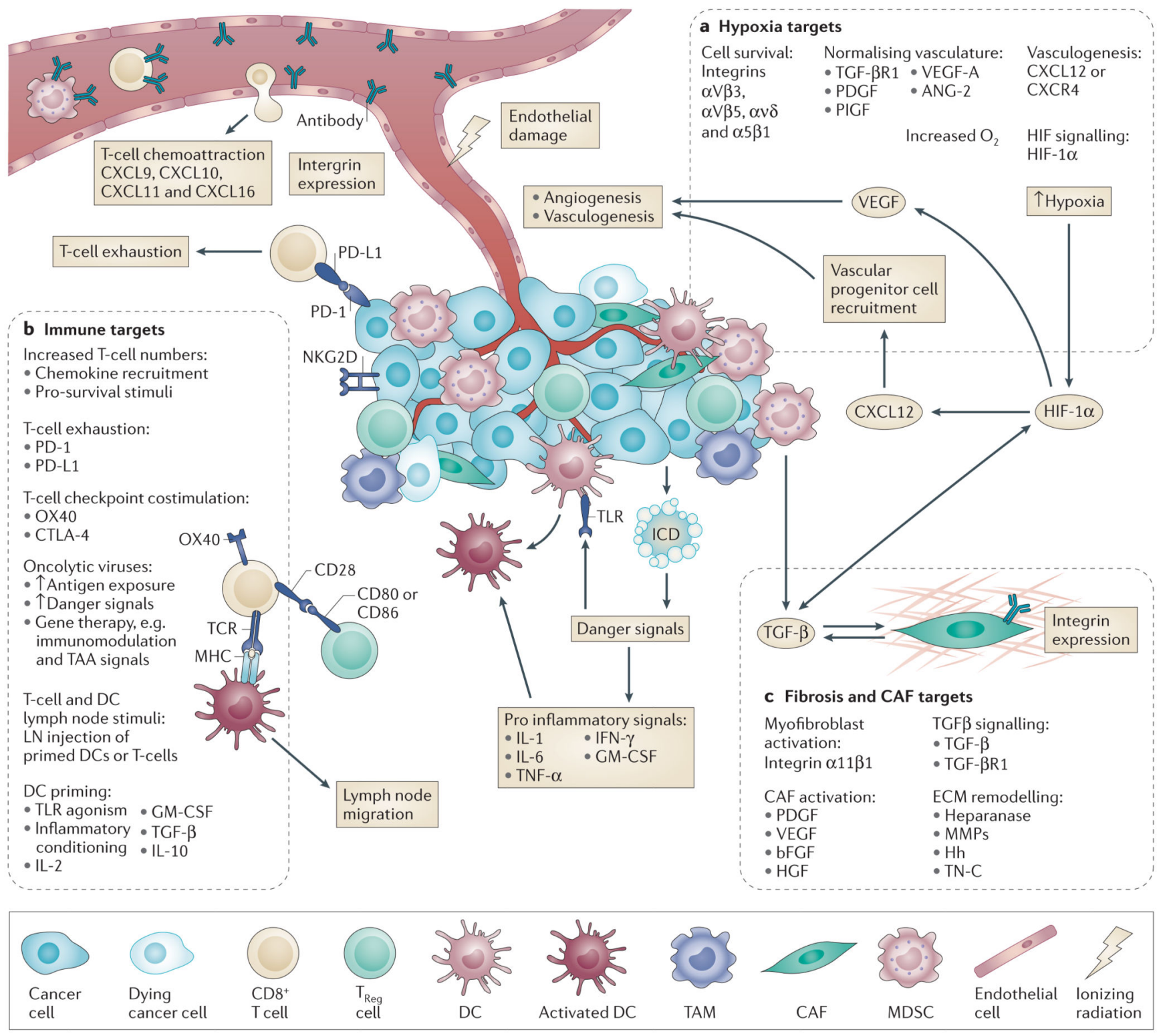

Figure 4. Targets for radiosensitisation

After radiotherapy, there are numerous potential targets within the tumour microenvironment (TME) whose modulation may lead to radiosensitisation. These are categorised broadly by area of biological effect - a) hypoxia, b) fibrosis and CAF related, and c) immune - and their actions portrayed in relation to the effects of radiotherapy on the TME summarised in Figure 1. Ongoing clinical trials addressing these in combination with radiotherapy are addressed in the Supplementary Table.

a) Hypoxia targets can be further subdivided into those that affect endothelial cell survival (for example, targeting integrins120), that normalise vasculature (for example, antagonising VEGF106), that prevent vasculogenesis (for example, targeting CXCL12 recruitment of endothelial progenitor cells25), that alter oxygen delivery (for example, ARCON therapy8587), or that alter HIF-1a signalling (for example, the HIF-1a inhibitor YC-1100). 
b) Fibrosis targets can be sub-categorised into those that affect stromal activation (for example, by inhibition of growth factors by suramin148), that affect ECM remodelling (for example, targeting TN-C with the antibody $81 \mathrm{C} 6135,136)$, or that affect TGF- $\beta$ signalling (for example, by targeting its receptor TGF- $\beta$ R1 with the inhibitor SD-208131).

c) Immune targets can be divided into those that prime dendritic cells (for example, the TLR7 agonist imiquimod166), that affect T-cell checkpoint co-stimulation (for example, the anti-CTLA-4 antibody ipilumimab74, 75, 171), that affect T-cell exhaustion (for example, the anti-PD-1 antibody Pembrolizumab181) or that affect T-cell recruitment (for example, targeting the chemokine CXCL16). Oncoviruses are also an immunomodulatory stimulus and can be used to affect multiple aspects of the immune pathway in the irradiated TME (for example, GM-CSF-expressing herpes simplex virus186, 188). 


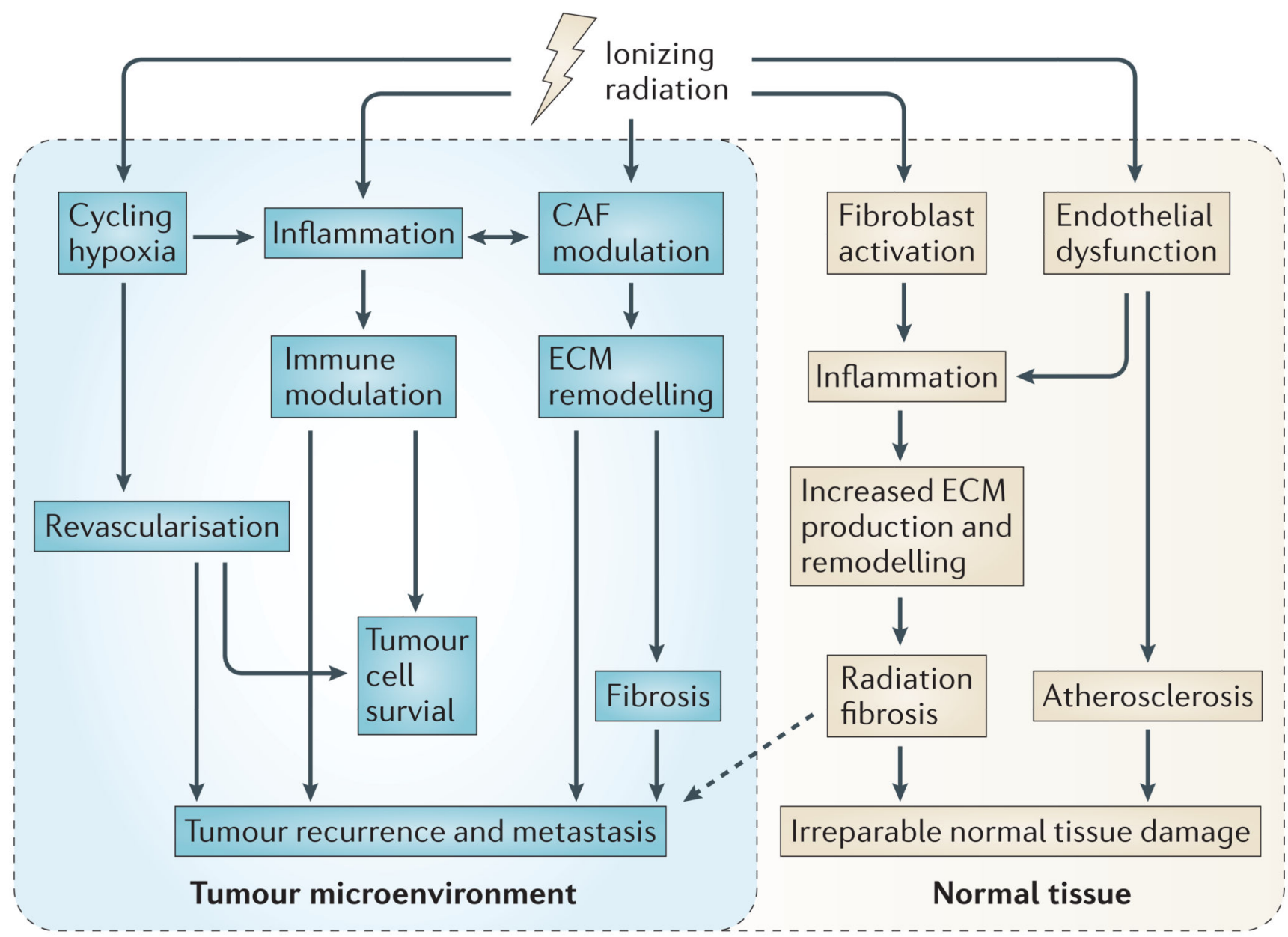

Figure 5. The interconnected radiotherapy-mediated changes in the tumour microenvironment (TME)

Hypoxic regions within the TME may initially affect tumour radiosensitivity. Radiotherapy elicits an inflammatory response in the TME as well as contributing to cycling hypoxia and modulation of CAF activity. These responses are interconnected with immunomodulation, revascularisation, ECM remodelling, and radiation fibrosis that may impact tumour cell survival and/or tumour recurrence and metastasis. Similar processes may occur in the surrounding normal tissue that could result in irreparable damage to critical organs. These events must all be taken into account when combining radiotherapy with therapies to modulate the immune response as well as reducing hypoxia and ECM remodelling and fibrosis in carefully timed treatment strategies. 
Table 1

Current and future TME targets for radiosensitisation

\begin{tabular}{|c|c|c|c|}
\hline Resistance mechanism & Drugs & Targets & Mode of action \\
\hline \multicolumn{4}{|l|}{ Immune response } \\
\hline \multirow{7}{*}{+2} & Ipilimumab & CTLA-4; & T-cell activation \\
\hline & Imiquimod & TLR7; & DC activation \\
\hline & Oncolytic viruses & Tumour cells & Activate immune response \\
\hline & \multirow[t]{2}{*}{ Future inhibitors } & IL-6, IL-10 & T-cell activation \\
\hline & & PD-1, PD-L1, TIM3, LAG3; & Prevent T-cell exhaustion \\
\hline & \multirow[t]{2}{*}{ Future agonists } & $\begin{array}{l}\text { GM-CSF, CXCL16, OX40, } \\
\text { CD40L, CD80, CD137 } \\
\text { (4-1BBL); }\end{array}$ & T-cell recruitment and activation \\
\hline & & $\begin{array}{l}\text { CCL3, CCL5, IL-2, IL-4, } \\
\text { IL-12, IRX-2; }\end{array}$ & Activate immune response \\
\hline \multicolumn{4}{|l|}{ Hypoxia } \\
\hline \multirow{10}{*}{ 每 } & Nitromidazole derivatives (i.e. Nimorazole) & Hypoxic cells & Reduce tumour hypoxia \\
\hline & Bioreactive albumin-MnO2 nanoparticles & Hypoxic cells & Reduce tumour hypoxia \\
\hline & Acriflavine, YC-1 & HIF-1a; & $\begin{array}{l}\text { Reduce hypoxia response } \\
\text { pathways }\end{array}$ \\
\hline & Aflibercept & $\begin{array}{l}\text { all VEGF molecules and } \\
\text { PlGF; }\end{array}$ & Vessel normalisation \\
\hline & AMG386 & ANG-1, ANG-2; & Inhibit pBMDC recruitment \\
\hline & Endostar & $\begin{array}{l}\text { VEGF, TGF- } \beta \text {, HIF-1a, } \\
\text { bFGF; }\end{array}$ & Inhibit angiogenesis \\
\hline & AMD3100 & CXCL12, CXCR4; & $\begin{array}{l}\text { Inhibit BMDC recruitment and } \\
\text { vasculogenesis }\end{array}$ \\
\hline & $\begin{array}{l}\text { Integrin inhibitors (i.e. Cilengitide, Vitaxin } \\
\text { and Volociximab) }\end{array}$ & Integrins av $\beta 3, a v \beta 5, \alpha 5 \beta 1$ & Inhibit angiogenesis \\
\hline & Future inhibitors & Integrins a $6 \beta 1, a 6 \beta 4$ & $\begin{array}{l}\text { Reduce EC survival and inhibit } \\
\text { angiogenesis }\end{array}$ \\
\hline & Future inhibitors & PlGF, ANG-2; & $\begin{array}{l}\text { Vessel normalisation and } \\
\text { overcome resistance to anti-VEGF } \\
\text { therapies }\end{array}$ \\
\hline \multicolumn{4}{|l|}{ Fibrotic processes } \\
\hline & BIBF1000, BIBF1120 & $\begin{array}{l}\text { PDGF, VEGF, bFGF } \\
\text { receptors; }\end{array}$ & $\begin{array}{l}\text { Reduce GF signalling and TME } \\
\text { remodelling; fibrosis }\end{array}$ \\
\hline & Imatinib, Nilotinib, Dasatanib & TGF- $\beta$, PDGF & GF signalling; collagen synthesis \\
\hline & Vismodegib, Saredigb, Sonedegib & SMO; & Reduce HH signalling; fibrosis \\
\hline & Suramin & $\begin{array}{l}\text { PDGF, EGF, TGF- } \beta, \text { FGF-2 } \\
\text { and IGF receptors and } \\
\text { heparanase enzymes; }\end{array}$ & $\begin{array}{l}\text { Reduce GF signalling and TME } \\
\text { remodelling; fibrosis }\end{array}$ \\
\hline & ST0001, PG545, M402, PI-88 & Heparanase; & Inhibit TME remodelling \\
\hline & SD-208 & TGF- $\beta$ RI; & Inhibit TGF- $\beta$ signalling \\
\hline & Simtuzumab & LOXL2; & $\begin{array}{l}\text { Reduce TME remodelling; liver } \\
\text { fibrosis }\end{array}$ \\
\hline & 81C6, F16SIP & $\mathrm{TN}-\mathrm{C}$ & $\begin{array}{l}\text { Reduce CAF-mediated TME } \\
\text { remodelling }\end{array}$ \\
\hline
\end{tabular}




\begin{tabular}{|l|l|l|l|}
\hline Resistance mechanism & Drugs & Targets & Mode of action \\
\hline & Future inhibitors & $\begin{array}{l}\text { HGF, CTGF, MMP-2, } \\
\text { MMP-3, Integrins a 11 } \beta 1, \\
\text { av } \beta 6 \text { and a 3 } \beta 1 ;\end{array}$ & $\begin{array}{l}\text { TME activation and remodeling; } \\
\text { radiation-mediated fibrosis }\end{array}$ \\
\hline
\end{tabular}

Abbreviations: ANG-1/-2, angiopoetin 1 and 2; bFGF, basic fibroblast growth factor; BMDC, bone marrow-derived cells; CTGF, connective tissue growth factor; CTLA-4, cytotoxic T- lymphocyte associated protein 4; DC, dendritic cells; EGF, epithelial growth factor; FGF-2, fibroblast growth factor 2; GF, growth factor; GM-CSF, granulocyte-macrophage colony-stimulating factor; HGF, hepatocyte growth factor; HH, hedgehog; HIF-1a, hypoxia inducible factor 1a; IGF, insulin growth factor; IRX2, iroquois homeobox 2; LAG3, lymphocyte activation gene 3; LOXL2, lysyl oxidaselike 2; MMP-2/ -3, matrix metalloproteinase 2 and 3; pBMDC, perivascular bone marrow-derived cells; PD-1, programmed death 1; PD-L1, programmed death ligand 1; PDGF, platelet-derived growth factor; PIGF, placental growth factor; SMO, smoothened; TGF- $\beta$, transforming growth factor $\beta$; TGF- $\beta$ R1, transforming growth factor $\beta$ receptor 1; TIM3, T-cell immunoglobulin mucin 3; TLR7, toll-like receptor 7; TME, tumour microenvironment; TN-C, tenascin C; VEGF, vascular endothelial growth factor 
Table 2

Fractionation of radiotherapy and Timing of immunomodulation

\begin{tabular}{|c|c|c|c|c|}
\hline Study type & Cancer type & Intervention & Outcome & Reference \\
\hline \multicolumn{5}{|l|}{ Fractionation } \\
\hline Preclinical & Murine glioma & $\begin{array}{l}\text { RT: } 10 \text { Gy in } 1 \text { fraction } \\
\text { Immunomodulation: Anti-PD-1 }\end{array}$ & $\begin{array}{l}\text { Longer survival seen (53 } \\
\text { days (RT and anti-PD-1) vs. } \\
25 \text { days (control), } 27 \text { days } \\
\text { (anti-PD-1) or } 28 \text { days (RT)) }\end{array}$ & $\begin{array}{l}\text { Zeng et al, } \\
2013190\end{array}$ \\
\hline Preclinical & Murine breast cancer & $\begin{array}{l}\text { RT: } 20 \text { Gy in } 1 \text { fraction, } 24 \text { Gy in } 3 \\
\text { fractions or } 30 \text { Gy in } 5 \text { fractions } \\
\text { Immunomodulation: Anti-CTLA-4 }\end{array}$ & $\begin{array}{l}\text { Best response seen in } 24 \mathrm{~Gy} \\
\text { in } 3 \text { fractions }\end{array}$ & $\begin{array}{l}\text { Dewan et al, } \\
2009171\end{array}$ \\
\hline Preclinical & Murine breast cancer & $\begin{array}{l}\text { RT: } 12 \text { Gy in } 1 \text { fraction, } 24 \text { Gy in } 2 \\
\text { fractions Immunomodulation: Anti- } \\
\text { CTLA-4 }\end{array}$ & $\begin{array}{l}\text { CD8+ T-cell anti-tumour } \\
\text { immunity demonstrated }\end{array}$ & $\begin{array}{l}\text { Demaria et al, } \\
2005191\end{array}$ \\
\hline Clinical & Hepatoma patients & $\begin{array}{l}\text { RT: } 8 \text { Gy in } 1 \text { fraction } \\
\text { Immunomodulation: DC vaccine }\end{array}$ & $\begin{array}{l}2 \text { partial responses, } 4 \text { minor } \\
\text { ones }\end{array}$ & $\begin{array}{l}\text { Chi et al, } \\
2005192\end{array}$ \\
\hline Clinical & Prostate cancer & $\begin{array}{l}\text { RT: } 70 \text { Gy in } 30 \text { fractions } \\
\text { Immunomodulation: IL-2 and GM-CSF }\end{array}$ & $\begin{array}{l}\text { PSA specific T-cells } \\
\text { increased }\end{array}$ & $\begin{array}{l}\text { Gulley et al, } \\
2005193\end{array}$ \\
\hline Clinical & MF & $\begin{array}{l}\text { RT: } 9-18 \text { Gy in } 9 \text { fractions } \\
\text { Immunomodulation: Injected TLR9 } \\
\text { agonist }\end{array}$ & $5 / 15$ responses & $\begin{array}{l}\text { Kim et al, } \\
2010194\end{array}$ \\
\hline \multicolumn{5}{|l|}{ Timing } \\
\hline Clinical & $\mathrm{MM}$ or $\mathrm{RCC}$ & $\begin{array}{l}\text { RT: } 60 \text { Gy in } 3 \text { fractions } \\
\text { Immunomodulation: IL-2 }\end{array}$ & $8 / 12$ responses & $\begin{array}{l}\text { Seung et al, } \\
2012195\end{array}$ \\
\hline Preclinical & $\begin{array}{l}\text { Murine Prostate } \mathrm{Ca} \\
\text { expressing } \mathrm{HA}\end{array}$ & $\begin{array}{l}\text { RT: } 15 \text { Gy } 1 \text { fraction } \\
\text { Immunomodulation: CD4+ T-cells } \\
\text { primed against HA (given at points on } \\
\text { a time-course after RT) }\end{array}$ & $\begin{array}{l}\text { Tolerance seen between days } \\
3 \text { and } 16 . \text { Normal T-cell } \\
\text { response by day } 33 \text {. }\end{array}$ & $\begin{array}{l}\text { Harris et al, } \\
200855\end{array}$ \\
\hline Clinical case report & $\mathrm{MM}$ & $\begin{array}{l}\text { RT: } 28.5 \text { Gy in } 3 \text { fractions } \\
\text { Immunomodulation: Ipilimumab (anti- } \\
\text { CTLA-4) at } 1 \text { month after RT }\end{array}$ & Complete response & $\begin{array}{l}\text { Postow et al, } \\
200974\end{array}$ \\
\hline Clinical case report & MM & $\begin{array}{l}\text { RT: } 54 \text { Gy in } 3 \text { fractions } \\
\text { Immunomodulation: Ipilimumab }\end{array}$ & Complete response & $\begin{array}{l}\text { Hiniker et al, } \\
201254\end{array}$ \\
\hline
\end{tabular}

Abbreviations: CTLA-4, cytotoxic T-lymphocyte associated protein 4; DC, dendritic cell; MM, malignant melanoma; MF, mycosis fungoides; PD-1, programmed death 1; PD-L1, programmed death ligand 1; PSA, prostate specific antigen; RCC, renal cell carcinoma; TLR, toll-like receptor; RT, radiotherapy; 